Portland State University

PDXScholar

Spring 5-22-2014

\title{
Temperature Dependent Transcription Initiation in Archaea: Interplay between Transcription Factor B and Promoter Sequence
}

Ming-Hsiao Wu

Portland State University

Follow this and additional works at: https://pdxscholar.library.pdx.edu/open_access_etds

Part of the Biology Commons

Let us know how access to this document benefits you.

Recommended Citation

Wu, Ming-Hsiao, "Temperature Dependent Transcription Initiation in Archaea: Interplay between Transcription Factor B and Promoter Sequence" (2014). Dissertations and Theses. Paper 2021. https://doi.org/10.15760/etd.2020

This Thesis is brought to you for free and open access. It has been accepted for inclusion in Dissertations and Theses by an authorized administrator of PDXScholar. Please contact us if we can make this document more accessible: pdxscholar@pdx.edu. 
Temperature Dependent Transcription Initiation in Archaea:

Interplay between Transcription Factor B and Promoter Sequence

\author{
by \\ Ming-Hsiao $\mathrm{Wu}$
}

A thesis submitted in partial fulfillment of the requirements for the degree of

\author{
Master of Science \\ in \\ Biology
}

Thesis Committee:

Michael Bartlett,Chair

Jeffrey Singer

Kenneth Stedman

Portland State University

2014 
(C) 2014 Ming-Hsiao Wu 


\begin{abstract}
In Pyrococcus furiosus (Pfu), a hyperthermophile archaeon, two transcription factor Bs, TFB1 and TFB2 are encoded in the genomic DNA. TFB1 is the primary TFB in $P f u$, and is homologous to transcription factor IIB (TFIIB) in eukaryotes. TFB2 is proposed to be a secondary TFB that is compared to TFB1, TFB2 lacks the conserved Bfinger / B-reader / B-linker regions which assist RNA polymerase in transcription start site selection and promoter opening functions respectively. P. furiosus, like all Archaea, encodes a single transcription factor E (TFE), that is homologous to the N-terminus of transcription factor II E (TFIIE) $\alpha$ subunit in eukaryotes. TFE stabilizes the transcription bubble when present, although it is not required for in vitro transcription. In this study, in vitro transcription is used to reveal how TFB2 responds to different temperature $\left(65^{\circ} \mathrm{C}\right.$, $70{ }^{\circ} \mathrm{C}, 75^{\circ} \mathrm{C}, 80{ }^{\circ} \mathrm{C}$, and $85^{\circ} \mathrm{C}$ ) at promoters for three different kinds of gene: nontemperature responsive, heat-shock induced, and cold-shock induced in the absence or presence of TFE. The activity of transcription complexes formed by TFB2 is always lower than by TFB1 in all temperatures and promoters. However, with heat-shock gene promoters, the activity of transcription complexes formed by TFB2 increases more than those formed with TFB1 with increasing temperatures. The temperature-dependent activities of TFB1 and TFB2 are similar with the non-temperature responsive gene promoter. With the cold-shock gene promoter, the activity of transcription complexes formed by both TFB1 and TFB2 has the highest activity in lower temperatures. When TFE is present, the activity of transcription complexes formed by TFB2 is enhanced with heat-shock gene promoters particularly at lower temperatures, and makes TFB2 behave
\end{abstract}


more similarly to TFB1. With the non-temperature responsive gene promoter, TFB2 still behaves similarly to TFB1 when TFE is present. However, with the cold-shock gene promoter, most of the activity of transcription complexes formed by TFB1 and TFB2 remain the same, but only the activity of TFB 1 decreases at $75^{\circ} \mathrm{C}$. The results suggest that TFB2 may play a role in heat-shock response through its increased sensitivity to temperature, and that TFE can modulate this temperature response. 


\section{Table of Contents}

Abstract

List of Tables $\quad$ V

List of Figures $\quad$ vi

INTRODUCTION

Transcription in three domains $\quad 2$

Comparison of archaeal and eukaryotic transcription 3

$\begin{array}{ll}\text { Archaeal transcription } & 4\end{array}$

$\begin{array}{ll}\text { Archaeal transcription regulation } & 6\end{array}$

$\begin{array}{ll}\text { Transcription factor IIB } & 6\end{array}$

$\begin{array}{lr}\text { Transcription factor IIE } & 8\end{array}$

$\begin{array}{lr}\text { Sigma factor in bacteria } & 8\end{array}$

Multiple TBPs and TFBs in archaea $\quad 9$

$\begin{array}{ll}\text { Promoter sequence elements } & 10\end{array}$

$\begin{array}{ll}\text { Two TFBs, TFB1 and TFB2, in Pyrococcus furiosus } & 10\end{array}$

MATERIALS AND METHODS 12

$\begin{array}{ll}\text { Protein purification } & 12\end{array}$

$\begin{array}{ll}\text { Promoter DNA templates } & 13\end{array}$

$\begin{array}{ll}\text { Transcription assay } & 15\end{array}$

$\begin{array}{ll}\text { RESULTS } & 16\end{array}$

TFB response to different temperatures and promoter sequences 16

Effect of TFE on TFB response to different temperatures and promoter sequences 28

$\begin{array}{ll}\text { CONCLUSION } & 37\end{array}$ 


\section{APPENDICES}

A: The function of aromatic amino acids in archaeal TFB B-reader motif

B: The function of XPB and XPD in archaea 


\section{List of Tables}

Table 1. Amplified promoter regions of Pf0687, Pf1137, Pf1602, and Pf1616. 


\section{List of Figures}

Figure 1 Archaeal transcription cycle. 5

Figure 2 Structure of yeast TFIIB and alignment with archaeal TFB. 7

Figure 3 Portion of promoter sequences used as transcription templates in this 17 study

Figure 4 Transcription activity with or without heparin at $75^{\circ} \mathrm{C}$. 18

Figure 5 Transcription activity of a non-temperature dependent promoter, Pf1602, using TFB1 or TFB2 in different temperatures.

Figure 6 Transcription activity of a heat-shock relative promoter, Pf0687, using TFB1 or TFB2 in different temperatures.

Figure 7 Transcription activity of a heat-shock relative promoter, Pf1616, using TFB1 or TFB2 in different temperatures.

Figure 8 Transcription activity of a cold-shock relative promoter, Pf1137, using TFB1 or TFB2 in different temperatures.

Figure 9 Transcription of the promoter for a non-temperature dependent gene, Pf1602, using TFB1 or TFB2 in different temperatures.

Figure 10 Transcription of the promoter for a heat-shock induced gene, Pf0687, using TFB1 or TFB2 in different temperatures.

Figure 11 Transcription of the promoter for a heat-shock induced gene, Pf1616, using TFB1 or TFB2 in different temperatures.

Figure 12 Transcription of the promoter for a cold-shock induced gene, Pf1137, using TFB1 or TFB2 in different temperatures.

Figure 13 Transcription activity of Pf1602 promoter with TFB mutants.

Figure 14 SDS-PAGE gel of aXPB and aXPD purification. 


\section{INTRODUCTION}

Bacteria, Archaea, and Eukarya are the three major domains in the universal tree of life $(1,2)$. Archaea, a prokaryotic group, thrive in most environments in the earth, and are famous for their extremophily. Many archaeal species are found in conditions of extreme $\mathrm{pH}$, temperature, salinity, and pressure $(3,4)$. Archaea and bacteria are singlecelled microorganisms, and lack a nucleus and intracellular organelles. At first, Archaea were classified as Bacteria. In 1977, Carl Woese and his group sequenced 16S ribosomal RNAs from 10 "methanogenic bacteria", and found out that these "bacteria" were only distantly related to typical Bacteria and formed a separate group, the Archaebacteria (5). Later, the "Archaebacteria" were renamed archaea. In 1990, a three-domain system, Bacteria, Archaea, and Eukaryota, was proposed based on rRNA sequence comparison (2).

The size of an archaeon is from 0.1 to 15 micrometer $(\mu \mathrm{m})$ in diameter, and the shape can be variable, such as rod, sphere, or spiral. The genome size of archaea ranges from $0.5 \mathrm{Mb}$ to $5.5 \mathrm{Mb}$ (6-8). Each of these characteristics of Archaea are shared with Bacteria. However, at the molecular level, Archaea are more similar to Eukaryotes in their information processing systems. The structure of RNA polymerase (RNAP) and the basal transcription factors in Archaea are more similar to those in Eukaryotes. Based on these characteristics, the Archaea are interesting microorganisms to study, especially for transcription and its regulation. 


\section{Transcription in the three domains}

Transcription is the first step of gene expression. RNA is made using DNA as a template, with the synthesis catalyzed by RNA polymerase (RNAP). Initiation, elongation, and termination are the three phases of transcription. The RNAP active site mechanism in Bacteria, Archaea, and Eukaryotes is conserved, but subunits of RNAP, transcription factors, and the mechanism of transcription initiation differ between bacteria, archaea, and eukaryotes.

In bacterial transcription initiation, the RNAP holoenzyme recognizes the promoter. A holoenzyme contains core RNA polymerase ( $\beta, \beta, \alpha \mathrm{I}, \alpha \mathrm{II}$, and $\omega$ subunits) with a sigma $(\sigma)$ factor. The $\sigma$ factor determines promoter specificity, positions the RNAP at the promoter, and assists in unwinding the double-stranded DNA (dsDNA) near the transcription start site (TSS) $(9,10)$. After the dsDNA is unwound, transcription begins, the $\sigma$ factor is released from the complex, and RNAP elongates the RNA transcript while reading along the DNA.

In eukaryotes, a mediator and six general transcription factors, TFIIA, TFIIB, TFIID, TFIIE, TFIIF, and TFIIH assist RNA polymerase II during initiation. TATA-box binding protein (TBP), a subunit of TFIID, is recruited to the TATA box in the promoter region, and then TFIIA and TFIIB bind and stabilize the TBP-DNA complex. Next, RNAP II with TFIIF are recruited to the complex. Last, TFIIE and TFIIH, which assist with promoter opening, are recruited to form the pre-initiation complex (PIC) (11-15). Mediator is a co-activator that binds RNA polymerase and is important for response to transcription regulators. After the dsDNA is unwound, the PIC initiates transcription. In 
the elongation phase, RNAP leaves the promoter region. The elongation factor, Spt4/5, associates with RNAP and stabilizes the elongation complex, and RNAP keeps transcribing RNA (16-18). In some cases, TFIIA, TFIID, TFIIE, TFIIH, and the mediator can still remain assembled at the promoter, and form a scaffold complex. This scaffold complex can act as a re-initiation complex, facilitating recruitment of a new RNAP II, making additional transcription initiation events easier and faster $(12,13,19)$.

The archaeal transcription machinery is more similar to eukaryotic than to bacterial transcription. Archaeal RNAP is similar to eukaryotic RNAPII in sequence homology and subunit identity. Archaeal transcription initiation in vitro requires TATAbox binding protein (TBP) and Transcription Factor B (TFB) which are homologous to eukaryotic TBP and Transcription Factor IIB (TFIIB) in eukaryotes respectively. Many Archaea possess multiple TFBs. While eukaryotes only possess one TFIIB, they do use other TFIIB-like transcription factors, such as TAF1B and Rrn7 which function with RNAP polymerase I, and Brf which functions with RNAP polymerase III (71- 73).

\section{Comparison of archaeal and eukaryotic transcription}

Archaea provide a useful model for studying the eukaryotic-type transcription mechanism for several reasons. First, being prokaryotic, archaeal genomes are small and encode fewer genes than eukaryotes which helps reduce complexity. Second, at the molecular level, archaea are remarkably similar to eukaryotes in DNA replication, transcription, and translation. Third, the subunits of RNA polymerase (RNAP) of Archaea and eukaryotes are highly conserved $(68,74)$. Fourth, important general transcription 
factors of Archaea and eukaryotes are homologous, including TF(II)B, TF(II)E, and TBP $(40,42,47,61)$. Fifth, many archaeal genomes contain histone homologs, that bind DNA and appear to assist in DNA packing (25-28). Although there are many similarities between eukaryotic and archaeal transcription, there are also important differences. First, three RNAPs (Pol I, Pol II, and Pol III) in eukaryotes synthesize ribosomal RNA (rRNA), messenger RNA (mRNA), and transfer RNA (tRNA) respectively. However, only one RNAP exists in Archaea for all purposes. Second, fewer general transcription factors are required for initiation in Archaea. Third, the regulation of archaeal transcription is more similar to bacterial transcription than to eukaryotic transcription $(31,33)$.

\section{Archaeal transcription}

Archaeal transcription initiation can be reconstituted in vitro with only RNA polymerase, the transcription factors TBP and TFB, and promoter DNA (61). Archaeal transcription starts with TATA box recognition. TBP recognizes the TATA box about 25 nucleotides upstream of the transcription start site, and TBP binds on the minor groove of the TATA box region and bends the double-stranded DNA to form a TBP-DNA complex (Fig 1A). Second, the C-terminal domain of TFB makes sequence-specific interaction with the $\mathrm{B}$ recognition element (BRE), located on the upstream region $\left(\mathrm{BRE}^{\mathrm{u}}\right)$ and downstream region $\left(\mathrm{BRE}^{\mathrm{d}}\right)$ of TATA box, forming the TBP-TFB-DNA complex (Fig 1B). Third, transcription factor E (TFE) associates with RNAP, and RNAP with TFE binds the TBP/TFB/DNA sub-complex to form a closed complex in which DNA is not yet unwound (Fig 1C,1D). Fourth, the N-terminal domain of TFB works with RNAP to 
unwind double-stranded DNA to form the transcription bubble, and the initiationcompetent open complex is formed (Fig 1E). Although TFE is not strictly required in in vitro transcription, it can facilitate transcription by stabilizing the interaction between TBP and TATA box, and it likely plays a role in the transition from closed complex to open complex $(17,34)$. Next, some abortive transcribed RNAs are produced (Fig 1F) (67). Then, Spt $4 / 5$ associates with this complex, and replaces TFE on the same RNAP binding site during the transition to elongation (Fig 1G) (17). Last, when the transcribed RNA is completed, RNAP falls off, and DNA can proceed to the next transcription event (Fig 1H).

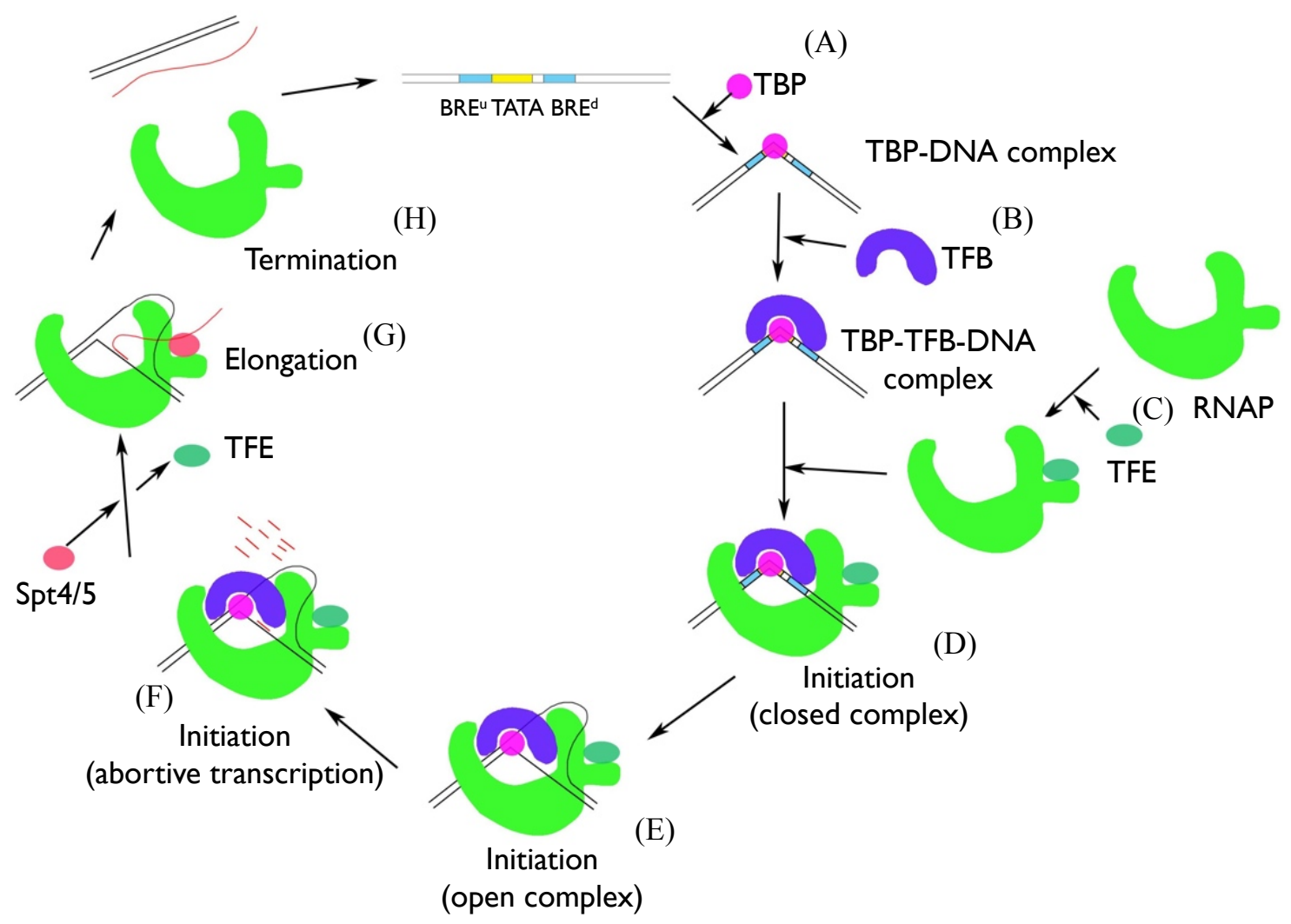

Figure 1. Archaeal Transcription cycle. See text for detail. 


\section{Archaeal transcription regulation}

Archaeal transcription regulation is more similar to bacterial transcription regulation in that repressor and activator proteins influence RNAP or transcription factor activity through direct interactions $(31,33)$. Several archaeal transcription regulators have been described, for instance, metal-dependent repressor 1(MDR1) in Archaeoglobus fulgidus, leucine-responsive regulatory protein (LrpA) in Pyrococcus furious, and Lrs14 in Sulfolobus solfataricus (35-38). MDR1 and LrpA act as negative transcription regulators and are homologous to bacterial metal-dependent transcriptional repressor, DtxR and bacterial leucine-regulatory protein family respectively. Both MDR1 and LrpA share a similar mechanism. Their binding sites overlap the promoter transcription start site (TSS), without affecting the binding of TFB and TBP, and prevent the recruitment of RNAP (35-37). On the other hand, Lrs14, another leucine-regulatory protein family member, binds sites overlapping the TATA box of regulated promoters. Lrs14 blocks TBP and TFB recruitment when binding on its promoter (38). Based on these observations, the transcription regulators of Bacteria and Archaea are similar.

\section{Transcription factor II B}

Transcription factor II B (TFIIB), a Pol II general transcription factor in eukaryotes, is required for transcription initiation, with specific functions in transcription start site (TSS) selection, promoter opening, and transcription bubble formation $(40,42)$. The C-terminal domain interacts with TBP, DNA, and Pol II, and contains B-core cyclin folds (39-42). The N-terminal domain of TFIIB contains a zinc ribbon/B-ribbon, B- 
finger/B-reader, and linker/B-linker, and interacts with Pol II (39-42). The B-ribbon contains a zinc ion and interacts with the dock domain of Pol II (39-42). The B-reader binds to the promoter DNA, recognizes the initiator element, and assists with TSS selection (39-42). The B-linker interacts with Rpb1 of Pol II and assists with promoter opening (39-42). Transcription factor B (TFB) in archaea is homologous to TFIIB in eukaryotes. Archaeal TFB serves the same function as eukaryotic TFIIB, and is generally highly conserved with eukaryotic TFIIB in all domains (Fig.2) (43-45).

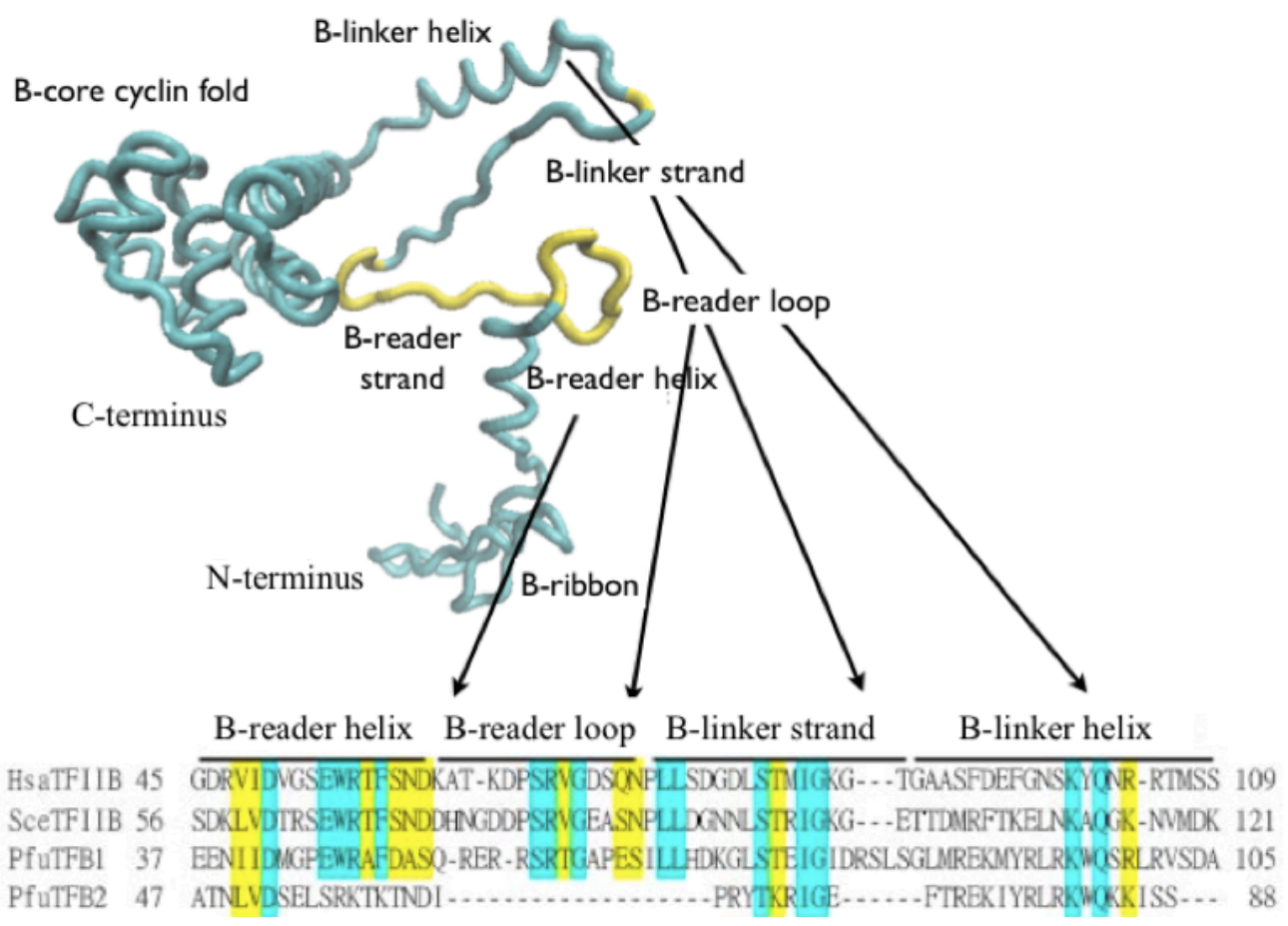

Figure 2. Structure of yeast TFIIB and alignment with archaeal TFB.

Only B-ribbon, B-reader, and B-linker motifs are shown. Yeast TFIIB is shown as a model to represent Pfu TFB1 (42, PDB: 4BBR); yellow regions represent the missing regions of Pfu TFB2. Initial alignment was done using CLUSTAL X, with manual realignment of TFB2, based on cross-linking results (Bhattarai and Bartlett, unpublished data) Hsa TFIIB :Homo sapiens TFIIB, Sce TFIIB: Saccharomyces cerevisiae TFIIB, Pfu TFB1: Pyrococcus furiosus TFB1, Pfu TFB2: Pyrococcus furiosus TFB2. 


\section{Transcription factor II E}

Transcription factor II E (TFIIE) is a pol II general transcription factor, and is composed of two subunits, $\alpha$ and $\beta$. (46). TFIIE stabilizes the pre-initiation complex (PIC), and is required with the helicase activity of TFIIH for unwinding promoter DNA to form a transcription bubble (47). Also, TFIIE can rescue inactive Pol II open complexes (48). Transcription factor E (TFE), a general transcription factor in archaeal transcription, is homologous to the N-terminus of transcription factor II E (TFIIE) $\alpha$ subunit in eukaryotes. TFE interacts with the non-transcribed strand in the open transcription bubble, and may function to stabilize the open complex $(17,34,47)$. TFE and Spt4/5, an archaeal elongation factor, bind to the same surface of RNAP, defined by a conserved coiled coil motif in the largest RNA subunit. During transcription elongation, Spt4/5 displaces the TFE to stimulate elongation $(17,48)$. Although TFE is not required for in vitro transcription, it facilitates transcription under certain conditions by stabilizing the transcription complex.

\section{Sigma factors in bacteria}

In Bacteria, promoter recognition and promoter opening are mediated by an interchangeable $\sigma$ factor. The main $\sigma$ factor in Escherichia coli $\left(\right.$ E.coli) is $\sigma^{70}$. The other six $\sigma$ factors in E.coli serve as accessory $\sigma$ factors that adjust transcription through altered promoter selectivity in response to environmental stresses. $\sigma$ factor serves a transcriptional function that is similar to eukaryotic TBP, TFIIB, and TFIIF, as well as archaeal TBP, TFB, and TFE. $\sigma^{70}$ factor recognizes the -35 and -10 elements on promoter, 
analogous to that TBP and TFIIB recognizing the TATA box, BRE, and transcription bubble respectively (50-52). Both $\sigma^{70}$ factor and TFIIB interact with promoter DNA and RNAP, and are involved in unwinding dsDNA during the transition from closed to open complex (Fig1D, 1E). In addition, both $\sigma^{70}$ factors and TFIIF have a negatively charged region that associates with the downstream DNA channel of RNAP (52).

\section{Multiple TBPs and TFBs in Archaea}

In Archaea, a species may possess multiple TBPs and TFBs. For instance, some halophilic archaea have 8 different TBPs and 12 different TFBs (53). Archaeal TFBs could have a similar function to bacterial $\sigma$ factors, and may play roles in responding to environment stresses, for instance, changes in salt concentration and exposures to UV irradiation $(54,55)$. The Thermococcus kodakaraensis (T.k.) genome encodes two TFBs, TFB1 and TFB2. The optimal salt concentrations for function of TFB1 and TFB2 in vitro are $\sim 200 \mathrm{mM} \mathrm{K}^{+}$and $\sim 250 \mathrm{mM} \mathrm{K}^{+}$respectively, so TFB2 could help the cell deal with osmotic shock (54). Sulfolobus solfataricus and Sulfolobus acidocaldarius genomes encode three TFBs, TFB1, TFB2, and TFB3. TFB1 is the primary TFB, TFB2 is normally expressed at a low level, and TFB3 is normally not expressed. However, TFB3 protein levels increase and may be responsible for increased transcription of other up-regulated gene following UV treatment (55). 


\section{Promoter sequence elements}

Promoters are DNA sequences that direct transcription, and have similarities across the three domains. There are several core elements, including the TATA box, B recognition element $\left(\mathrm{BRE}^{\mathrm{u}}\right.$ and $\left.\mathrm{BRE}^{\mathrm{d}}\right)$, and initiator element (Inr) in archaeal and eukaryotic promoters, and the -35 element and -10 element in bacterial promoters. The TATA box is usually located 25 nucleotides upstream of the transcription start site (TSS) and is bound by TBP (65). The B recognition element is located at short sequence upstream and downstream of TATA box, and is bound by TF(II)B (66). The transcription start site (TSS) is located at the initiator element (Inr). Each promoter has its own intrinsic promoter strength, measured as the number of transcripts produced over a specific time period. Promoter strength is often determined by the affinity of transcription factors or RNA polymerase for the promoter, and is directed by the specific sequence of the promoters. Promoter sequence can also direct transcription in response to environmental stress through interaction with alternate basal transcription factors (56). For example, in E.coli, heat-shock promoters contain the consensus sequences, TNTCNCCCTTGAA in the -35 element and CCCCATTTA in -10 element $(\mathrm{N}=$ any nucleotide) that interact with regions 4.2 and 2.4 of the $\sigma^{32}$ subunit of RNA polymerase (57).

\section{Two TFBs, TFB1 and TFB2, in Pyrococcus furiosus}

Pyrococcus furiosus (Pfu), a hyperthermophile archaeon, has a single gene encoding TBP, but has two genes encoding TFB homologs, TFB1 and TFB2. TFB1 is the 
primary TFB in $P f u$, and it is highly conserved with TFIIB in eukaryotes (Fig 2).

Compared to TFB1, TFB2 is not conserved in the B-reader and B-linker regions, which normally play a role in selecting the transcription start site and unwinding doublestranded DNA (Fig 2) (39-42). In vivo, heat-shock increases the mRNA level of $P f u$ TFB2, but not $P f u$ TFB1 (60). Although TFB2 lacks important and conserved sequences, it has been shown to function in transcription initiation. The transcription efficiency of $P f u$ TFB2 in vitro is always weaker than that of $P f u$ TFB1 at $65^{\circ} \mathrm{C}(61)$. However, addition of TFE can stabilize the PIC and somewhat increase the transcription efficiency of $P f u$ TFB2 (61). Although how $P f u$ TFB2 responds to higher temperature, and the overall function of $P f u$ TFB2 are not clear yet, we predict that $P f u$ TFB2 is involved in the heat-shock response, and may increase transcription of heat-shock promoters including its own promoter (Pf0687).

In this study, in vitro transcription assays are used to reveal how Pfu TFB1 and TFB2 respond to different temperatures $\left(65,70,75,80\right.$, and $\left.85^{\circ} \mathrm{C}\right)$ and different promoters (two heat-shock promoters, a cold-shock promoter, and a temperatureindependent promoter). We predict that TFB2 will have higher activity with a heat-shock promoter at higher temperature, that it will not function well at a cold-shock promoter, and that TFE facilitates TFB2 transcription under conditions where promoter opening is difficult. 


\section{MATERIALS AND METHODS}

\section{Protein purification}

Recombinant Pyrococcus furiosus TBB, TFB1, and TFB2 proteins were prepared as described previously (61). The genes were amplified by PCR and cloned into the vector pET21b. The encoded proteins with six-histidine tag at the N-terminus were overexpressed in an E.coli host, and the protein was purified by $\mathrm{Ni}^{2+}$ ion chromatography. Two different washing protocols were employed for purification of TFB2, non-denaturing and denaturing. Since TFB2 overexpressed well but did not bind well to the $\mathrm{Ni}^{2+}$ column under native conditions, it seemed likely that the six-histidine tag is inaccessible in the folded protein. Therefore, a denaturing wash protocol was used to denature the protein and reveal the six-histidine tag to be bound by $\mathrm{Ni}^{2+}$ ion. The protein was refolded on the column by reducing the denaturant concentration. Non-denaturing wash buffers were used in TBP and TFB1 purification. The non-denaturing wash buffers contain $0.02 \mathrm{M}$ NaHEPES pH8, 0.007M MgCl2, 0.5M NaCl, 5\% (vol/vol) Tween20, 0.01-0.2M imidazole ( $\mathrm{pH} 7)$, and 10\% (vol/vol) glycerol. The denaturing wash buffers are used for TFB2 because the yield of TFB2 is extremely low in non-denaturing purification. The denaturing chromatography protein purification utilized wash $1,2,3$, elute 1 , and elute 2 solutions. The wash 1 solution containd 0.02M NaHEPES pH8, 0.007M MgCl2, 0.5M $\mathrm{NaCl}, 5 \%$ (vol/vol) Tween20, 0.01M imidazole ( $\mathrm{pH} 7$ ), 10\% (vol/vol) glycerol, and 8M urea. The wash 2 solution was the same as the wash 1 solution but with $0.02 \mathrm{M}$ imidazole ( $\mathrm{pH} 7$ ). The wash 3 solutions was the same as the wash 2 solution, but with $3 \mathrm{M}$ urea. The 
elute 1 and 2 solutions were the same as the wash 3 solution, but with $0.2 \mathrm{M}$ imidazole (pH 7). Proteins were concentrated, and buffer was changed to standard TFB storage buffer (containing 0.5M NaCl, 0.02M Tris pH 8, 0.001M EDTA pH 8) using Microspin concentration (3000 MW cut-off). The transcription activities of TFB protein purified by non-denaturing versus denaturing proteins have been checked, and have similar transcription activity (data not shown). Native $P f u$ RNAP was purified from Pyrococcus furiosus cell lysate as described previously, and was a gift from I. Waege and W. Hausner (62).

\section{Promoter DNA templates}

Three predicted temperature-responsive promoters used in this study were chosen based on data from cold-shock and heat-shock studies $(60,63)$. Promoter regions were identified in the Pyrococcus furiosus genome using the archaeal genome browser (http:// archaea.ucsc.edu/). Predicted TATA box sequences were identified by similarity to the consensus sequence TTTATATA (70), and regions containing the predicted promoter were amplified from Pyrococcus furiosus genomic DNA by PCR (primer sequences are shown in Table 1). The positions of each promoter region according to the annotation of Robb et al. (64) are as follows: for Pf0687, positions 695239 to 695540, for Pf1137, positions 1088879 to 1089033 , and for Pf1616 positions 1508306 to 1508519 . A fourth promoter for the glutamate dehydrogenase gene (Pf1602) was chosen as a non-temperature responsive promoter that was previously well-characterized. PCR products were quantified by spectrophotometer. 
Table 1. Amplified promoter regions of Pf0687, Pf1137, Pf1602, and Pf1616.

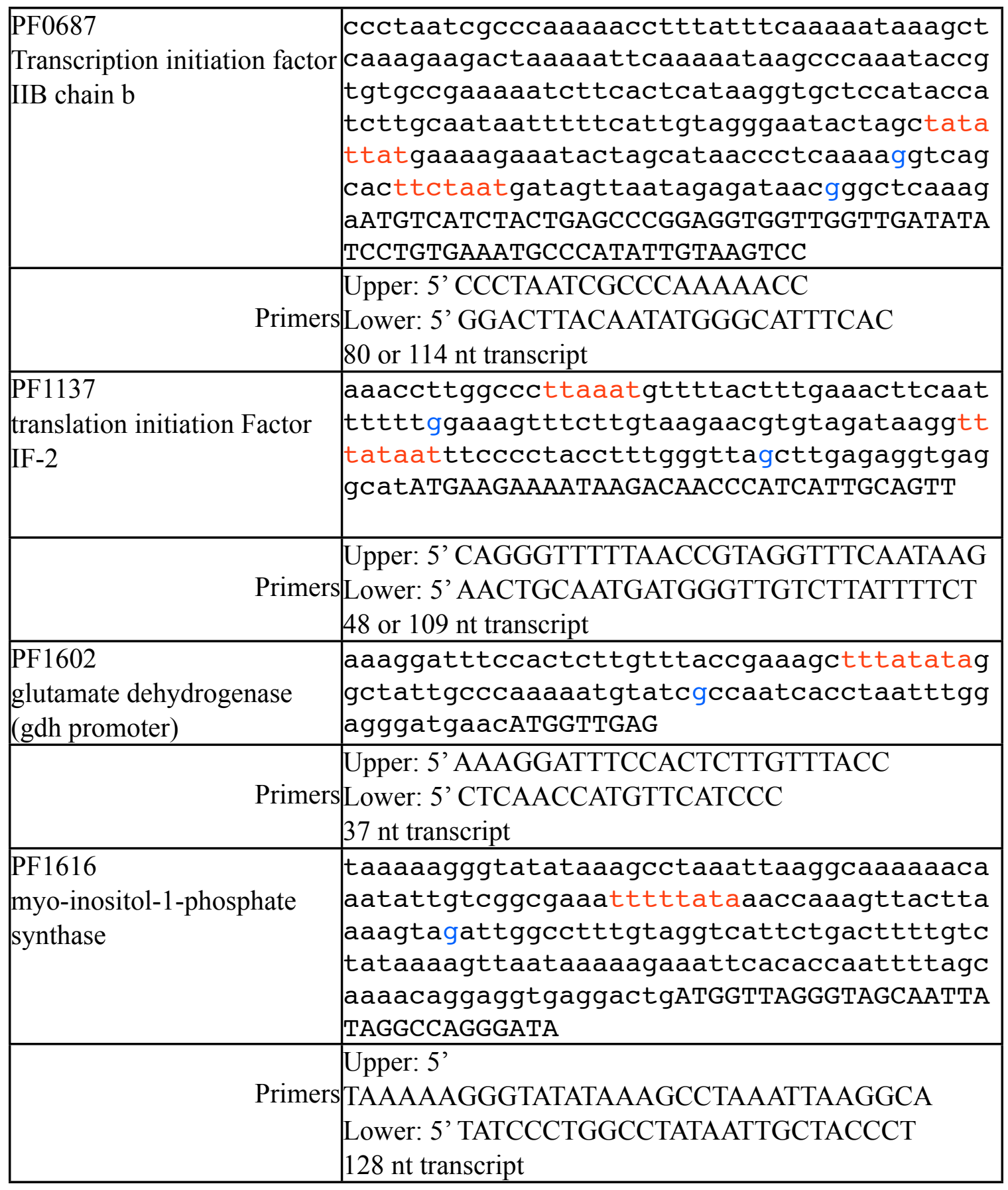

Upper-case letters represent translated region; lower-case letters represent intergenic sequences. Potential TATA-boxes are highlighted in red, Predicted transcription start site are highlighted in blue. 


\section{Transcription assay}

Transcription reactions were performed as described previously (61). The $12.5 \mu 1$ cocktail reaction mixtures contained $0.025 \mathrm{M} \mathrm{MgCl}_{2}, 0.25 \mathrm{M} \mathrm{NaCl}, 0.0001 \mathrm{M}$ EDTA, 0.04M Na-HEPES (pH 7.3), 0.005M $\beta$-mercaptoethanol, 5\% (vol/vol) glycerol, $0.1 \mu \mathrm{g}$ $\mu \mathrm{l}^{-1}$ bovine serum albumin; $10 \mathrm{nM}$ promoter DNA was combined with $60 \mathrm{nM}$ TBP, 60 nM TFB1, or $60 \mathrm{nM}$ TFB2, $10 \mathrm{nM}$ RNAP, and 200nM TFE when needed. The reaction mixtures were heated at $65{ }^{\circ} \mathrm{C}, 70{ }^{\circ} \mathrm{C}, 75^{\circ} \mathrm{C}, 80{ }^{\circ} \mathrm{C}$, and $85{ }^{\circ} \mathrm{C}$ in a thermal cycler for 40 min. Ribonucleotide triphosphates $(500 \mu \mathrm{M}$ GTP, $500 \mu \mathrm{M} \mathrm{CTP}, 500 \mu \mathrm{M}$ ATP, and $10 \mu \mathrm{M}$ $\left.\left[\alpha^{32} \mathrm{P}\right] \mathrm{UTP}\left[\sim 40 \mathrm{Ci} \mathrm{mmol}^{-1}\right]\right)$ were added to initiate transcription. After $20 \mathrm{~min}$ incubation, the reactions were stopped by adding $12 \mu 1$ stop buffer ( $8 \mathrm{M}$ urea, $0.05 \mathrm{M}$ EDTA, 0.09M Tris-borate buffer, $\mathrm{pH} 8.3,0.02 \%$ bromphenol blue, and $0.02 \%$ xylene cyanol). Before loading to the $14 \%$ polyacrylamide gel, reactions were heated at $95{ }^{\circ} \mathrm{C}$ for $3 \mathrm{~min}$. The gel was analyzed by phosphorimaging as described $(61,65)$. ImageQuant was used to quantify data. The area surrounding a transcript band was selected and quantified, and an area of the same size in the same lane was quantified and subtracted as background. The transcript level at $65{ }^{\circ} \mathrm{C}$ for each TFB / Promoter combination was set to 1.0 , and values at other temperatures were normalized to this value. Both M1 and M2 markers were made from known-length sizes of glutamate dehydrogenase gene (gdh, Pf1602) promoter ( -60 to +37 and -60 to +84$)$. All TFB transcription activities in transcription assays were tested in three independent experiments and averaged. Error bars, representing standard deviation, were from the three independent experiments. 


\section{RESULTS}

Pyrococcus furiosus is one of the best-studied Archaea for transcription. The Pyrococcus furiosus genome encodes two different TFB genes, TFB1 and TFB2. The TFB1 protein shows high sequence, structure and function of similarity with TFIIB. However, TFB2 has sequence divergence with TFB1(Fig 2), and the function of TFB2 is not well-known. By studying TFB2, the function of the missing motifs and the response of different promoters to environmental changes will be more obvious, which could assist in understanding the genetic determinants of environmental stress response in Pyrococcus furiosus. To determine the function and role of TFB2 in Pyrococcus furiosus, I have performed experiments that test the response of TFB2 to changing temperature. Transcription directed by TFB2 was compared with TFB1 at promoters for temperatureresponsive genes in the absence or presence of TFE.

\section{TFB response to different temperatures and promoter sequences}

Because of the specific increase in TFB2 mRNA following heat-shock reaction, I predict that TFB2 is important for the heat shock response, perhaps by selective transcription of other heat-shock related genes. To test the idea that TFB2 transcribes heat-shock dependent genes, I used in vitro transcription assays to determine the activity of both TFB1 and TFB2 in different temperatures and promoters. These results demonstrate at which temperature and with which promoter TFB2 would have better activity. 
Four selected promoter DNAs, transcription factor B 2 (Pf0687), translation initiation factor (Pf1137), a glutamate dehydrogenase (Pf1602), and a myo-inositol-1phosphate synthase (Pf1616), were tested in this research. Pf1602 promoter is widely used in research and its transcription does not change in response to temperature change in vivo. In vivo, the mRNA level of Pf0687 and Pf1616 promoters increased following a shift from $90{ }^{\circ} \mathrm{C}$ to $105^{\circ} \mathrm{C}$, which represents a heat-shock response (60). The mRNA level from the Pf1137 gene increased following a shift from $95{ }^{\circ} \mathrm{C}$ to $72{ }^{\circ} \mathrm{C}$ which represents a cold-shock response (63). The transcription start site of Pf1602 was previously determined. The potential transcription start site of the other three promoters were predicted and indicated by the black bars (Fig 3).

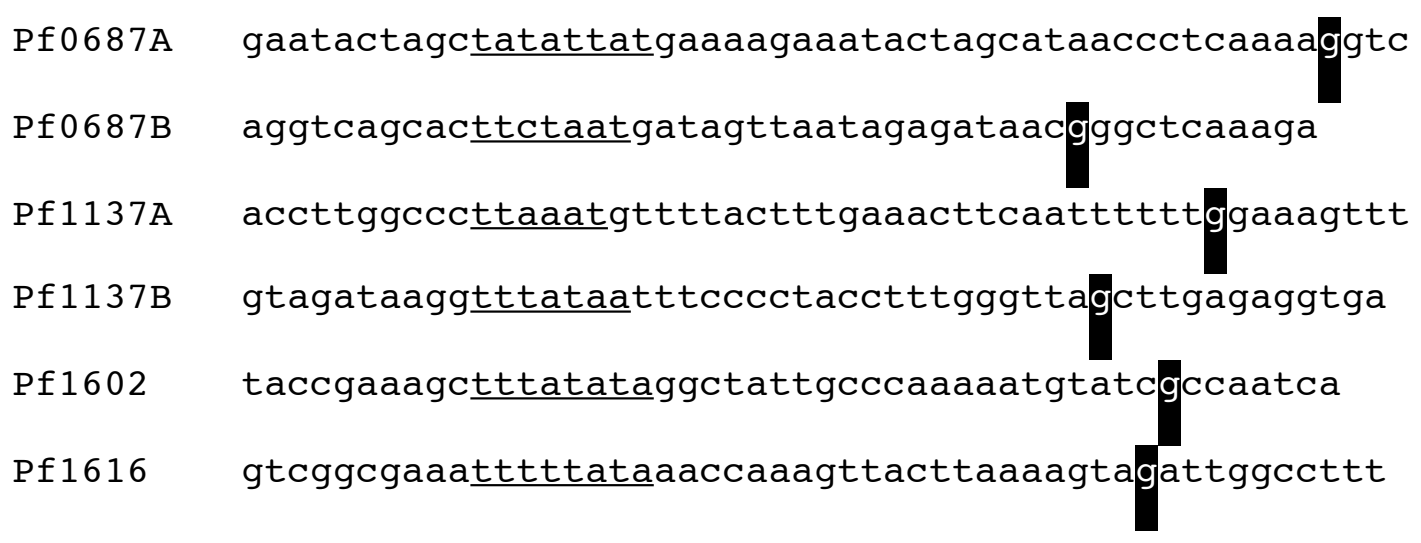

Figure 3. Portion of promoter sequences used as transcription templates in this study. Predicted TATA boxes are underlined, and the potential transcription start sites are shown in a black background.

Heparin is a poly-sulfated polysaccharide that sequesters many DNA-binding proteins, and can be used to prevent non-specific RNAP binding to the DNA, important 
in assays such as electrophoretic mobility shift assay (EMSA), foot-printing, and crosslinking. However, I found that the activity of transcription complexes containing TFB1 and TFB 2 are affected by adding heparin. Specifically, TFB2 is more heparin sensitive than TFB1 (Fig 4). Based on this result, heparin was not used in this study.

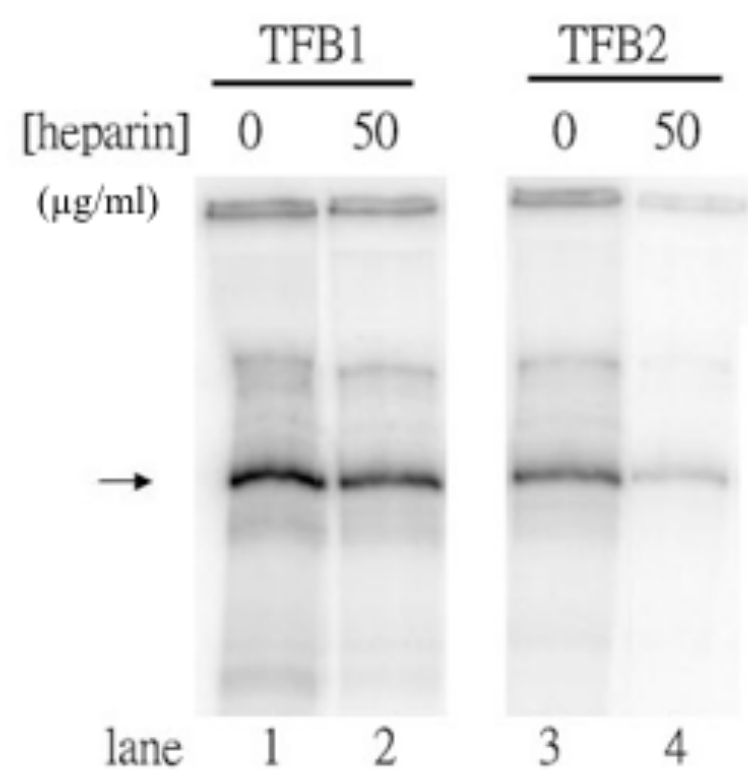

Figure 4. Transcription activity with or without heparin at $75^{\circ} \mathrm{C}$. Transcription was performed using Pf1616 promoter. Reactions 2 and 4 were treated with heparin for 30 seconds prior to addition of NTPs.

To determine a baseline behavior for TFB2, I compared its activity in transcription with TFB1 on the well-studied glutamate dehydrogenase gene (gdh, Pf1602) promoter. Transcription reactions were performed at 5 temperatures $\left(65^{\circ} \mathrm{C}, 70{ }^{\circ} \mathrm{C}, 75^{\circ} \mathrm{C}, 80^{\circ} \mathrm{C}\right.$, and $85^{\circ} \mathrm{C}$ ). While optimum growth occurs at $95^{\circ} \mathrm{C}$ to $100^{\circ} \mathrm{C}$ for $P$. furiosus, growth can still occur at $70{ }^{\circ} \mathrm{C}$. Previous experiments have shown that transcription complexes can be formed and promoter-specific initiation can occur at $65^{\circ} \mathrm{C}$, while transcription at 90 ${ }^{\circ} \mathrm{C}-95{ }^{\circ} \mathrm{C}$ is inhibited, presumably because of linear temperature denaturation (43). 
The promoter for Pf1602 gene is predicted to be less responsive to temperature because Pf1602 mRNA level does not change with heat or cold shock. I observed that transcription complexes formed with TFB1 were more active than TFB2 in all temperatures (Fig 5A). With increasing temperature, transcription complexes containing TFB1 produced increasing amounts of the run-off product with a maximum at $80{ }^{\circ} \mathrm{C}$, and a reduction at $85{ }^{\circ} \mathrm{C}$ (Fig 5A lanes 1-4). Similarly, the activity of the transcription complexes containing TFB2 increased from $65^{\circ} \mathrm{C}$ to $70{ }^{\circ} \mathrm{C}$ (Fig 5A lanes 7-8), reached a maximum at $75{ }^{\circ} \mathrm{C}$ to $80{ }^{\circ} \mathrm{C}$ (Fig 5A lanes 9-10), and decreased at $85{ }^{\circ} \mathrm{C}$ (Fig 5A lane 9). The transcription level relative to $65^{\circ} \mathrm{C}$ increases gradually in response to temperature for both TFB1 and TFB2. At $80^{\circ} \mathrm{C}$, transcription relative to $65^{\circ} \mathrm{C}$ was 2.56 -fold and 3.38fold higher with TFB1 and TFB2, respectively. For the Pf1602 promoter, the trend line of TFB2 is close to that of TFB1 (Fig 5B), indicating that TFB1 and TFB2 respond to temperature similarly at the promoter of a temperature insensitive gene. 
A.

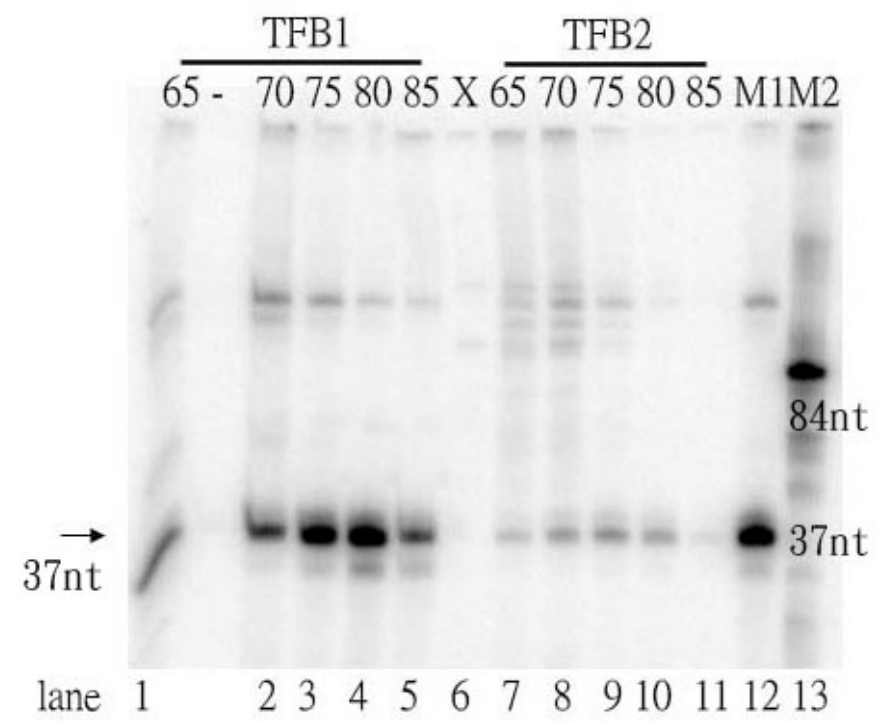

B.

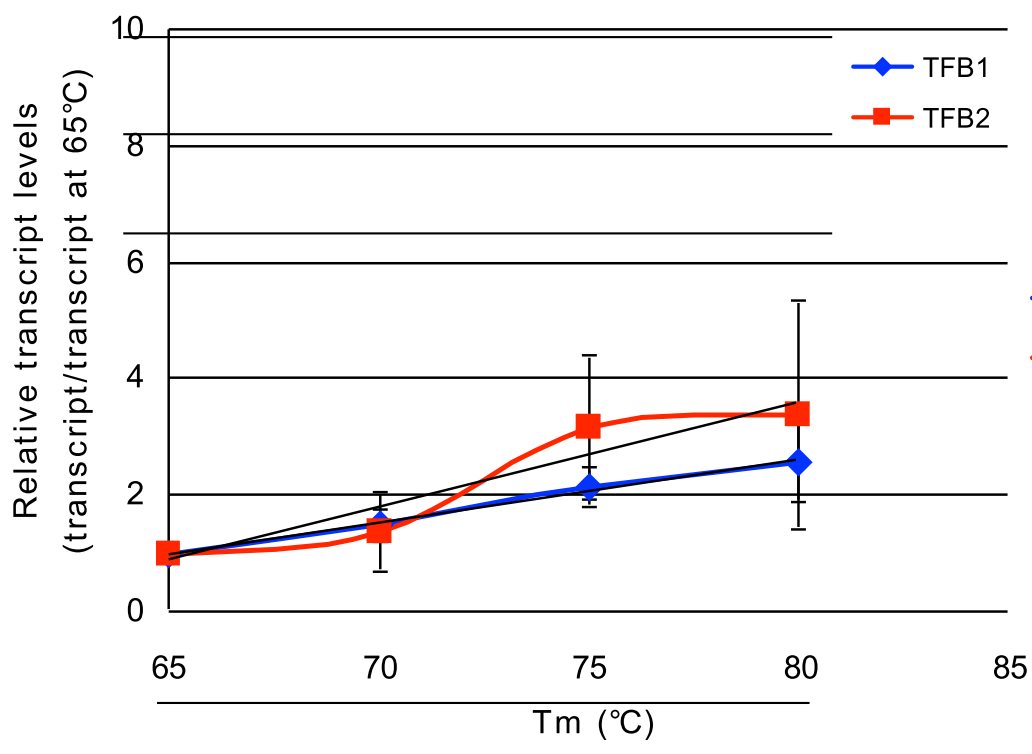

Figure 5. Transcription activity of a non-temperature dependent promoter, Pf1602, using TFB1 or TFB2 in different temperatures. (A) Activities of the transcription complexes formed with TFB1 or TFB2 with Pf1602 in different temperatures $\left(65-85^{\circ} \mathrm{C}\right)$. The promoter-dependent transcripts are indicated by the arrow. X: no TFB at $75^{\circ} \mathrm{C}, \mathrm{M} 1: 37 \mathrm{nt}$ marker, M2: 84 nt marker. (B) Transcription response to temperature relative to $65^{\circ} \mathrm{C}$ of TFB1 and TFB2 with Pf1602. Quantitation of the transcription activity of different temperatures with Pf1602 normalized to the activity of its own activity at $65^{\circ} \mathrm{C}$. Blue 
diamond represents TFB1, and red square represents TFB2. Error bars represent standard deviation (SD) from three independent experiments.

To determine the response of a putative heat shock promoter to temperature change, the promoter for the TFB2 gene (Pf0687) was chosen for analysis because the mRNA level of TFB2 increased dramatically during heat shock (60). Transcription reactions including TFB1 were more active than those with TFB2 in all temperatures. Two principal transcripts were observed, one of $\sim 80 \mathrm{nt}$, and the other of $\sim 114 \mathrm{nt}$, suggesting two promoters are active in this region upstream of the Pf0687 gene (Fig 1). The temperature-dependent activity of the transcription complexes containing TFB1 was similar to the response of the promoter of the temperature-independent gene (Pf1602) (Fig 6A lanes 1-5). The activity of the transcription complexes containing TFB2 was very low at $65{ }^{\circ} \mathrm{C}$ ( Fig $6 \mathrm{~A}$ lane 7), increased from $70{ }^{\circ} \mathrm{C}$ to $80{ }^{\circ} \mathrm{C}$ ( Fig $6 \mathrm{~A}$ lanes $8-10$ ), and nearly disappeared at $85^{\circ} \mathrm{C}$ ( Fig $6 \mathrm{~A}$ lane 11). Relative to transcription at $65^{\circ} \mathrm{C}$, TFB1 increased more than TFB2 at $70{ }^{\circ} \mathrm{C}$. However, the relative increase for TFB2 became higher at $75{ }^{\circ} \mathrm{C}$ and $80^{\circ} \mathrm{C}$. Both TFB1 and TFB2 reached their maxima at $80^{\circ} \mathrm{C}$. At $80{ }^{\circ} \mathrm{C}$, transcription activity of $80 \mathrm{nt}$ transcript relative to $65^{\circ} \mathrm{C}$ was about 3.52 -fold and 8.92-fold higher with TFB1 and TFB2, respectively (Fig 6B); transcription activity of $114 \mathrm{nt}$ transcript relative to $65^{\circ} \mathrm{C}$ was about 1.88 -fold and 4.17 -fold higher with TFB1 and TFB2 (Fig 6C). At Pf0687, although TFB2's activities were always lower than TFB1's, the rate of TFB2 transcription increased more than TFB1 with increasing temperature for two potential transcribed regions. 
A.

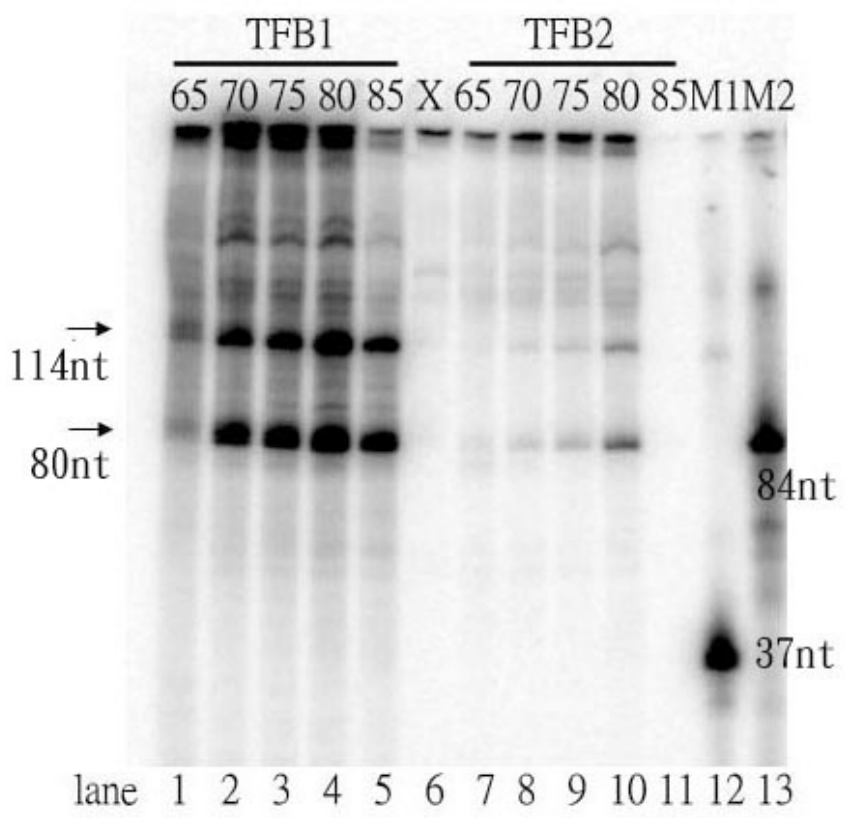

B.

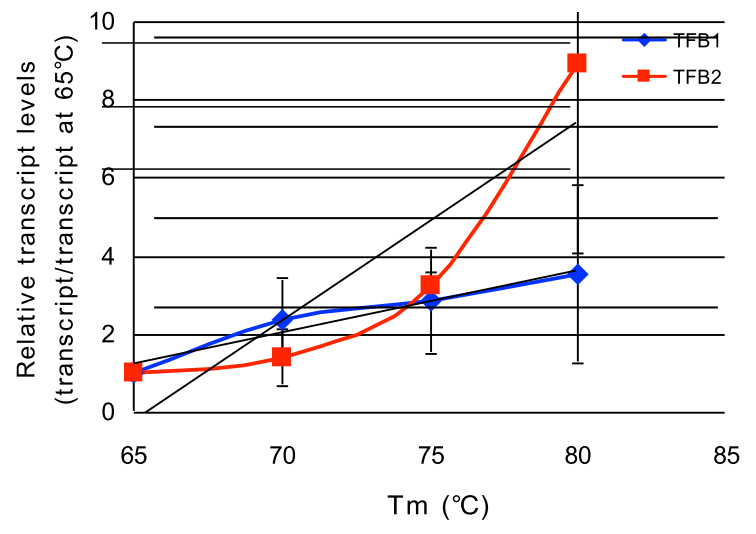

C.

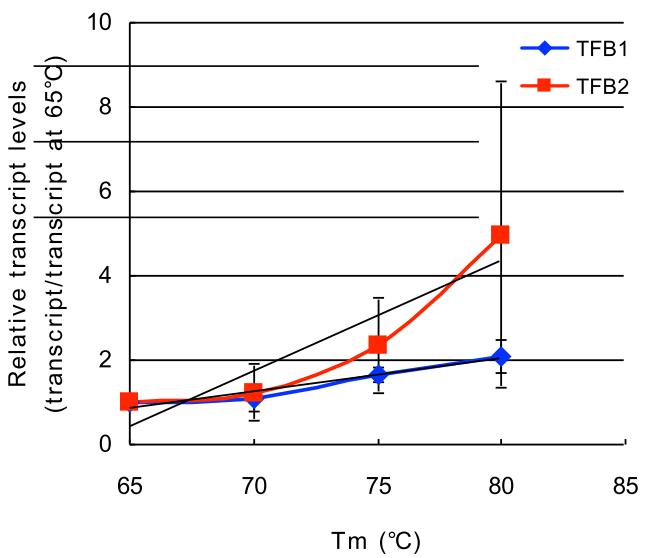

Figure 6. Transcription activity of a heat-shock relative promoter, Pf0687, using TFB1 or TFB2 in different temperatures. (A) Activities of the transcription complexes formed with TFB1 or TFB2 with Pf0687 in different temperatures $\left(65-85^{\circ} \mathrm{C}\right)$. The promoterdependent transcripts are indicated by the arrow. X: no TFB at $75^{\circ} \mathrm{C}, \mathrm{M} 1: 37 \mathrm{nt}$ marker, M2: $84 \mathrm{nt}$ marker. (B) Transcription response to temperature relative to $65^{\circ} \mathrm{C}$ of TFB1 and TFB2 with Pf0687 (80 nt). (C) Transcription response to temperature relative to 65 ${ }^{\circ} \mathrm{C}$ of TFB1 and TFB2 with Pf0687 (114 nt). Quantitation of the transcription activity of different temperatures with Pf0687 normalized to the activity of its own activity at $65{ }^{\circ} \mathrm{C}$. Blue diamond represents TFB1, and red square represents TFB2. Error bars represent standard deviation (SD) from three independent experiments. 
To determine whether other promoters for heat shock induced genes had enhanced temperature response to TFB2, the promoter of a myo-inositol-1-phosphate synthase (Pf1616) was tested because the mRNA level of TFB2 increased dramatically during heat shock (60). The activities of the transcription reactions containing TFB1 were more active than those containing TFB2 in all temperatures. The activity of the transcription complexes containing TFB1 increased from $65^{\circ} \mathrm{C}$ to $80^{\circ} \mathrm{C}$ (Fig 7A lanes 1-4), and decreased dramatically at $85^{\circ} \mathrm{C}$ (Fig $7 \mathrm{~A}$ lane 5 ). The activity of the transcription complexes containing TFB2 was very low at $65^{\circ} \mathrm{C}$ (Fig 7A lane 7), increased from $65^{\circ} \mathrm{C}$ to $80^{\circ} \mathrm{C}$ (Fig 6A lanes 8-10), and disappeared at $85^{\circ} \mathrm{C}$ (Fig 7A lane 11). The response of TFB1 transcription complex increased slowly in response to temperature, but constantly. It reached a maxima (about 2.58 -fold) at $80^{\circ} \mathrm{C}$. The response of TFB2 to temperature was higher than of TFB1. At $80^{\circ} \mathrm{C}$, the response transcription with of TFB2 was about 6.69-fold higher than at $65^{\circ} \mathrm{C}$ (Fig 7B). At Pf1616, although the activity of the transcription complexes formed with TFB2 was always less active than the one with TFB1, the transcription complex with TFB2 increased more than TFB1 from $65^{\circ} \mathrm{C}$ to 80 ${ }^{\circ} \mathrm{C}$. 
A.

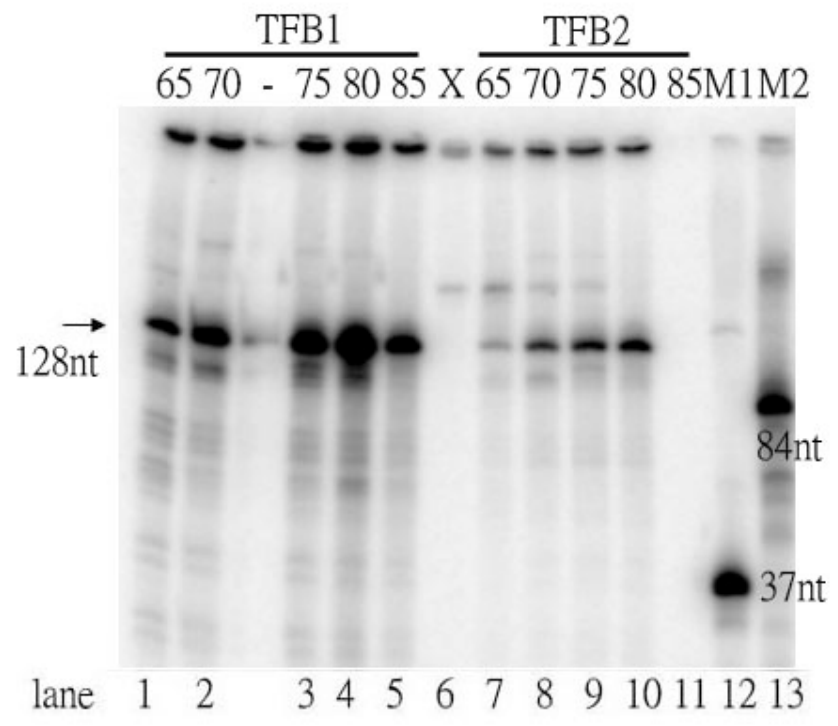

B.

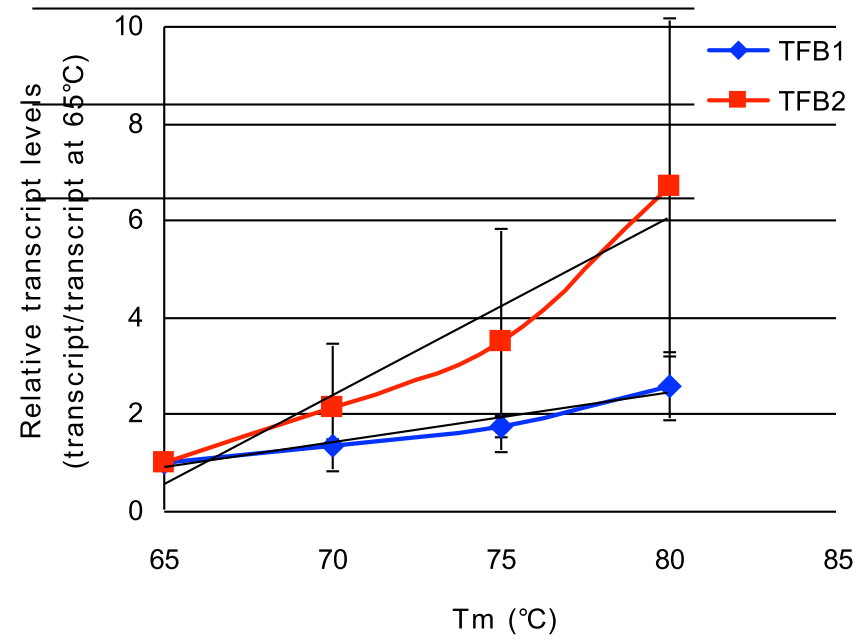

Figure 7. Transcription activity of a heat-shock relative promoter, Pf1616, using TFB1 or TFB2 in different temperatures. (A) Activities of the transcription complexes formed with TFB1 or TFB2 with Pf1616 in different temperatures $\left(65-85^{\circ} \mathrm{C}\right)$. The promoterdependent transcripts are indicated by the arrow. X: no TFB at $75^{\circ} \mathrm{C}, \mathrm{M} 1: 37 \mathrm{nt}$ marker, M2: $84 \mathrm{nt}$ marker. (B) Transcription response to temperature relative to $65^{\circ} \mathrm{C}$ of TFB1 and TFB2 with Pf1616. Quantitation of the transcription activity of different temperatures with Pf1616 normalized to the activity of its own activity at $65^{\circ} \mathrm{C}$. Blue diamond represents TFB1, and red square represents TFB2. Error bars represent standard deviation (SD) from three independent experiments. 
To see how the TFB1 or TFB2 associated transcription complexes function with a promoter for a cold-shock induced gene, the promoter of the translation initiation factor IF-2 (Pf1137) was used. The mRNA level from Pf1137 was previously shown to increase 1.6 fold following cold-shock (63). In this experiment, two principal transcripts were observed, one of $\sim 48 \mathrm{nt}$, and the other of $\sim 109 \mathrm{nt}$, suggesting two promoters are active in this region upstream of the Pf1137 gene (Fig 1). For the short transcript (48 nt), transcription complexes formed with TFB1 associated with this promoter to transcribe RNA (Fig 8A lanes 1-5) although at a very low level. However, no transcripts were detected for TFB2 (Fig 8A lanes 7-11). The activity of the transcription complexes formed with TFB1 increased with increasing temperature slowly (Fig 8A lanes 1-5), reached the maximum (about 3.63 -fold) at $80{ }^{\circ} \mathrm{C}$ (Fig 8B). For the long transcripts (109 nt), TFB1 or TFB2 was not required to produce a transcript (Fig 8A lane 6). Interestingly, the activity of transcription complexes formed with TFB1 and TFB2 reaches a maximum at $70{ }^{\circ} \mathrm{C}$ (Fig $8 \mathrm{~A}$ lanes 2,8 ), and then decreased at $75^{\circ} \mathrm{C}, 80^{\circ} \mathrm{C}$, and $85^{\circ} \mathrm{C}$. (Fig $8 \mathrm{~A}$ lanes 3-5, 9-11). This result showed TFB2-directed transcription complexes do not yield detectable transcription for shorter transcript (48 nt) in this promoter. However, another possible transcript had a higher transcription activity in lower temperatures for both TFB1 and TFB2 $\left(65-70{ }^{\circ} \mathrm{C}\right)$. It is notable that the larger transcript can be made by RNA polymerase in the absence of TFB, but that adding TFB1 or TFB2 increases transcript levels. Site-specific transcription by archaeal RNA polymerase in the absence of TFB has not been previously reported. 
A.

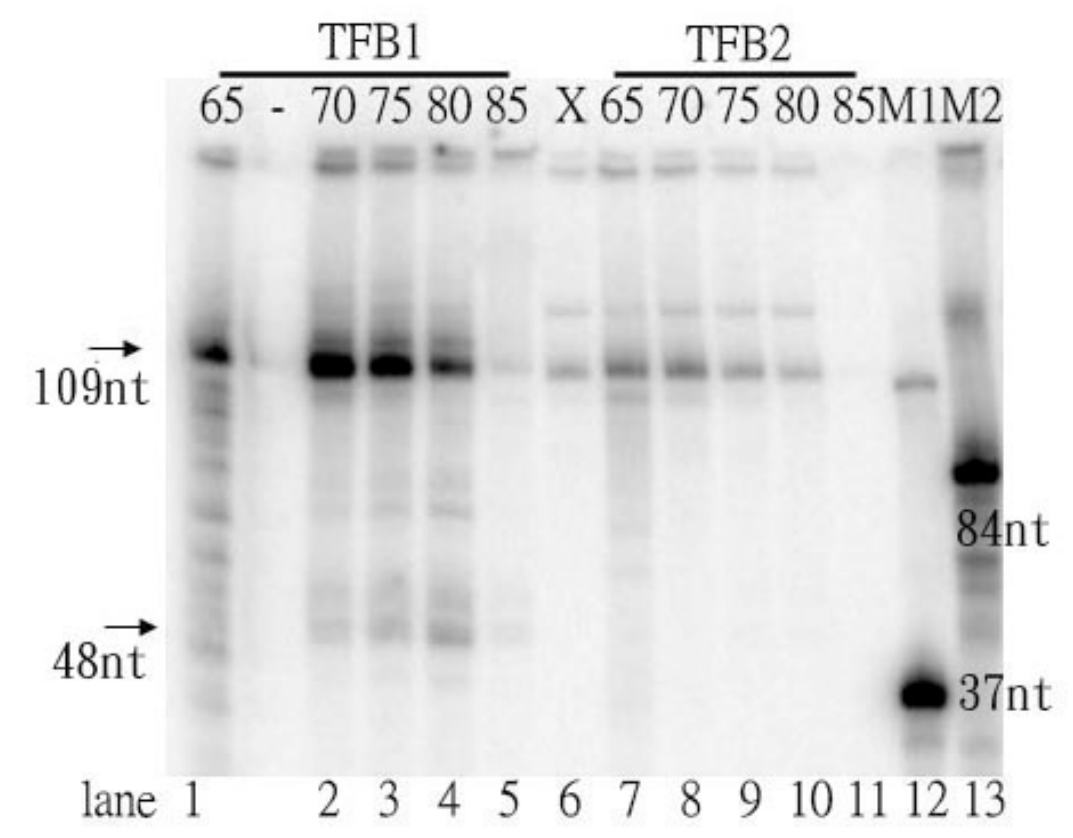

B.

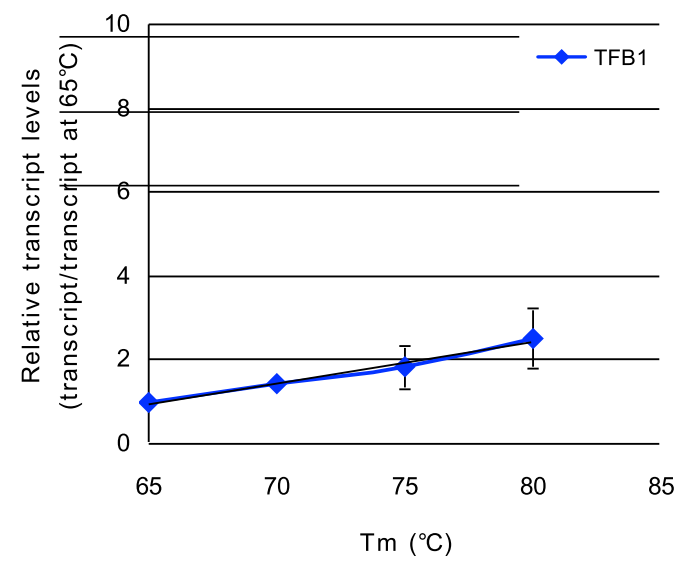

C.

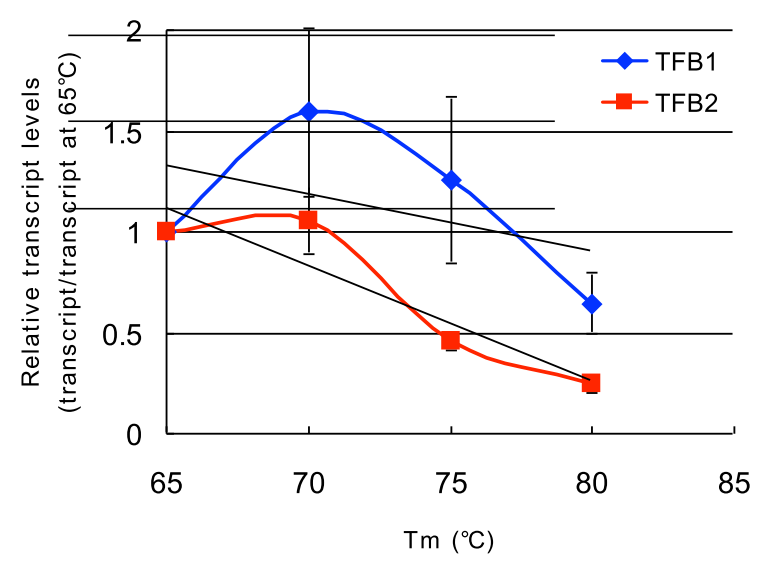

Figure 8. Transcription activity of a cold-shock relative promoter, Pf1137, using TFB1 or TFB2 in different temperatures. (A) Activities of the transcription complexes formed with TFB1 or TFB2 with Pf1137 in different temperatures $\left(65-85^{\circ} \mathrm{C}\right)$. The promoterdependent transcripts are indicated by the arrow. X: no TFB at $75^{\circ} \mathrm{C}, \mathrm{M} 1: 37 \mathrm{nt}$ marker, M2: 84 nt marker. (B) Transcription response to temperature relative to $65{ }^{\circ} \mathrm{C}$ of TFB1 and TFB2 with Pf1137 (48 nt). (C) Transcription response to temperature relative to 65 ${ }^{\circ} \mathrm{C}$ of TFB1 and TFB2 with Pf1 137 (109 nt). Quantitation of the transcription activity of different temperatures with Pf1137 normalized to the activity of its own activity at $65{ }^{\circ} \mathrm{C}$. Blue diamond represents TFB1. Error bars represent standard deviation (SD) from three independent experiments. 
These experiments illustrate a differential response of TFB1 and TFB2 to temperature changes that is promoter dependent. TFB2 behaved very similarly to TFB1 with the temperature-independent gene promoter (Pf1602). TFB2 increased transcription activity more than TFB1 with increasing temperature when it associated with promoters for heat-shock induced gene (Pf0687 and PF1616). TFB2 did not yield measurable transcription for the short transcript (48 nt) from the cold-shock promoter (Pf1137). However, TFB2 behaved similarly to TFB1 with the long transcript (109 nt) from the cold-shock promoter (Pf1137). 


\section{Effect of TFE on TFB response to different temperatures and promoter sequences}

Transcription factor E (TFE) is able to increase the activity of RNA polymerase by stabilizing the pre-initiation complex (PIC) (61). It has been shown previously that TFB2 is inefficient in promoter opening, and that TFE can partly compensate for this defect. To determine whether the differential response of TFB1 and TFB2 to temperature persists in the presence of TFE, I tested the same four promoters for response to temperature with or without addition of TFE.

At the gdh (Pf1602) promoter, the activities of the transcription complexes formed with TFB1 were more active than with TFB2 in all temperatures. At all temperatures, transcription complexes with TFB1 showed minimal activation by TFE (Fig 9A and 9B). In contrast, TFE increased the activity of the transcription complexes formed with TFB2 at all temperatures; especially at $70{ }^{\circ} \mathrm{C}$ (Fig 9A and 9B). The transcription response to temperature in the presence of TFE was similar for TFB1 and TFB2, and the maximum activity (relative to $65^{\circ} \mathrm{C}$ ) at $80^{\circ} \mathrm{C}$ was about 2.81 -fold and 2.48 -fold with TFB1 and TFB2, respectively (Fig 9C). 
A.

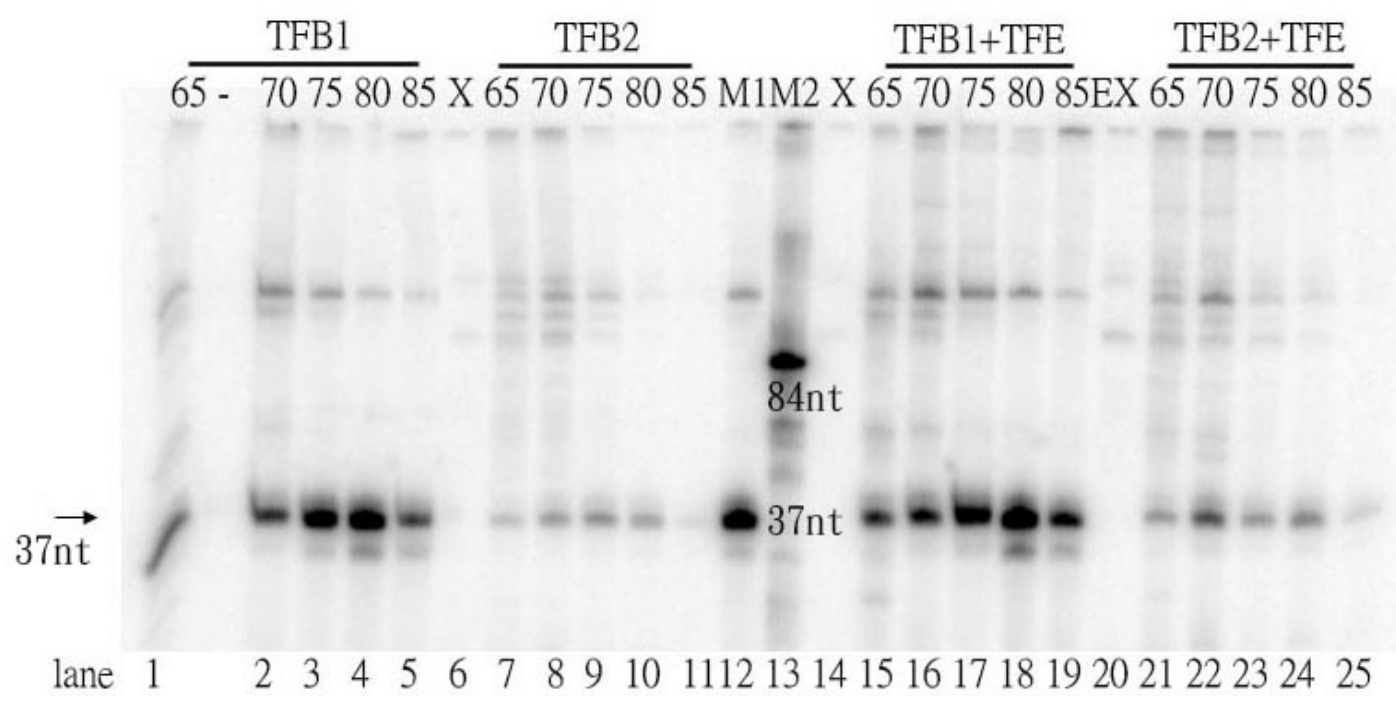

B.

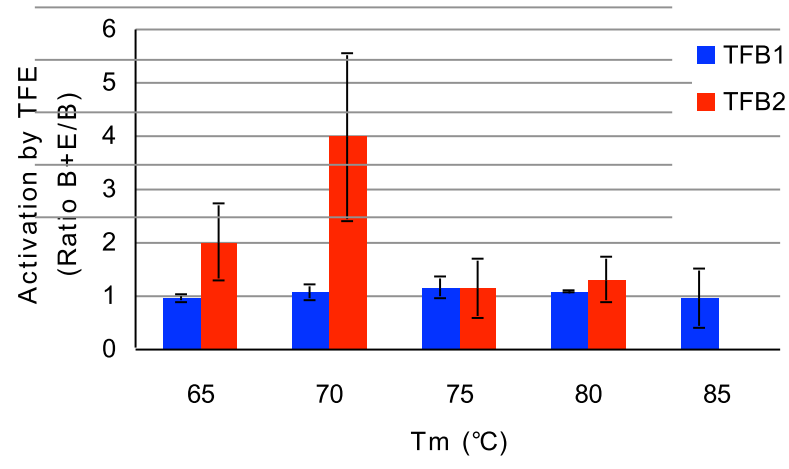

C.

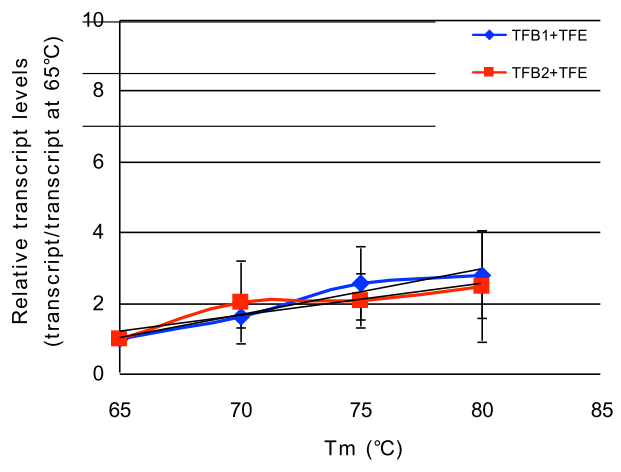

Figure 9. Transcription of the promoter for a non-temperature dependent gene, Pf1602, using TFB1 or TFB2 in different temperatures. (A) Activities of the transcription complexes formed with TFB1, TFB2, TFB1+TFE, or TFB2+TFE with Pf1602 in different temperatures $\left(65-85^{\circ} \mathrm{C}\right)$ The promoter-dependent transcripts are indicated by the arrow. X: no TFB at $75^{\circ} \mathrm{C}, \mathrm{EX}$ : no TFB, but with TFE at $75^{\circ} \mathrm{C}, \mathrm{M} 1: 37$ nt marker, M2: 84 nt marker. (B) Transcription activity comparison of TFB1 and TFB2 with Pf1602 in the presence and absence of TFE. The ratio of transcription activity with TFE to without TFE is shown. (C) Transcription response to temperature relative to $65^{\circ} \mathrm{C}$ of TFB1+TFE and TFB2+TFE with Pf1602. Quantitation of the transcription activity of different temperatures with Pf0687 normalized to the activity of its own activity at $65{ }^{\circ} \mathrm{C}$. Blue (diamond) represents TFB1, and red (square) represents TFB2. Error bars represent standard deviation (SD) from three independent experiments. Figure 5A and Figure 8A are the image from the same gel. 
In Pf0687 (TFB2, a heat shock induced gene), the activity of the transcription complexes formed with TFB1 was higher than with TFB2 in all temperatures. With TFE, the activity of the transcription complexes containing TFB1 increased with temperature, but decreased dramatically at $85{ }^{\circ} \mathrm{C}$ for both short and long transcripts ( $80 \mathrm{nt}$ and $114 \mathrm{nt}$ ) (Fig 10A lanes 15-19). The activity of the transcription complexes containing TFB2 also increased with temperature for both short and long transcripts ( $80 \mathrm{nt}$ and $114 \mathrm{nt}$ ), and some transcription at $85^{\circ} \mathrm{C}$ was seen (Fig 10A lanes 21-25). For the short transcript (80 nt), the comparison of with and without TFE showed that TFE did not enhance the activity of the transcription complexes formed with TFB1, since the activity of the transcription complexes formed with TFB1 and TFE almost stayed the same (Fig 10B) However, for the long transcript (114 nt), the activity of complexes formed with TFB1 decreased at $65^{\circ} \mathrm{C}$ when TFE was present (Fig 10D).For both short and long transcripts, TFE enhanced the activity of the transcription complexes formed with TFB2, especially at lower temperatures $\left(65^{\circ} \mathrm{C}\right.$ and $\left.70{ }^{\circ} \mathrm{C}\right)($ Fig 10B, 10D). In the presence of TFE, transcription at $80^{\circ} \mathrm{C}$, relative to $65^{\circ} \mathrm{C}$, was similar for TFB1 and TFB2 for the short transcript for the short transcript (4.81-fold and 4.29-fold with TFB1 and TFB2, respectively). However, for the long transcript, the activity of the transcription complexes formed with TFB1 at $80{ }^{\circ} \mathrm{C}$ relative to $65^{\circ} \mathrm{C}$ was much higher than those of TFB2 (5.4fold and 2.5-fold with TFB1 and TFB2, respectively). The similar response of TFB1 and TFB2 to temperature in the presence of TFE contrasts with the differential response in the absence of TFE (Fig 6B, Fig 10C, and Fig 10E). 
A.

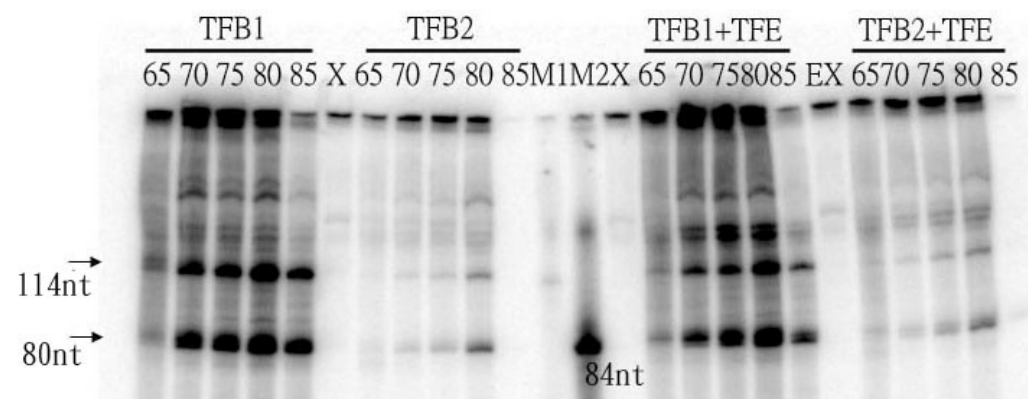

$37 n t$

lane $1120 \begin{array}{lllllll}2 & 4 & 6 & 7 & 8 & 9 & 10111213141516171819202122232425\end{array}$

B.

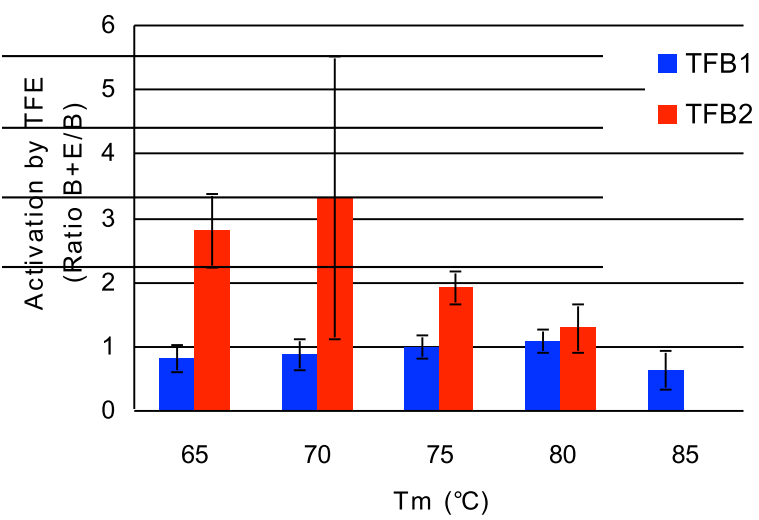

D.

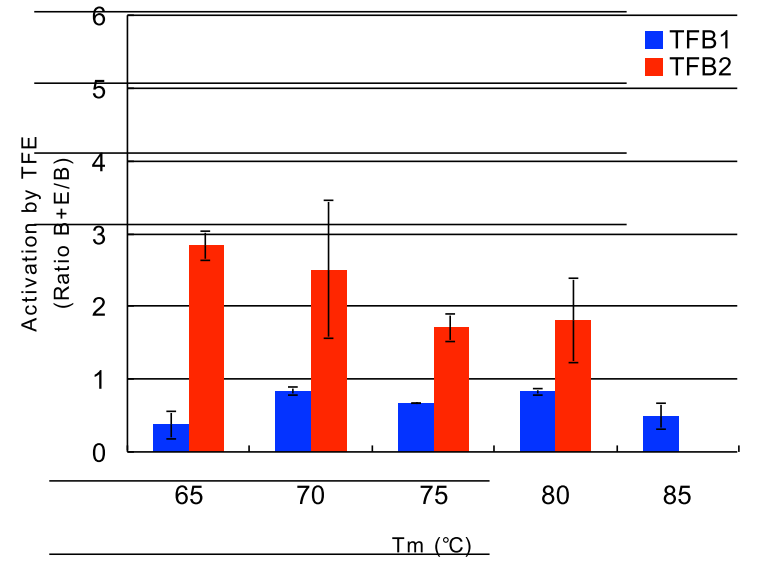

C.

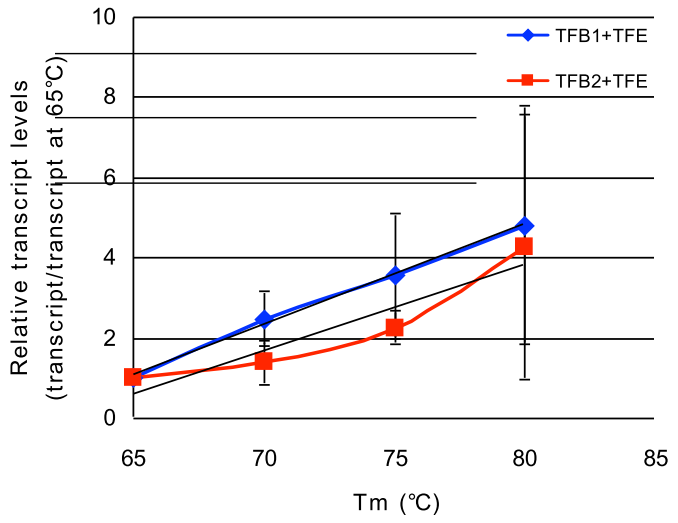

E.

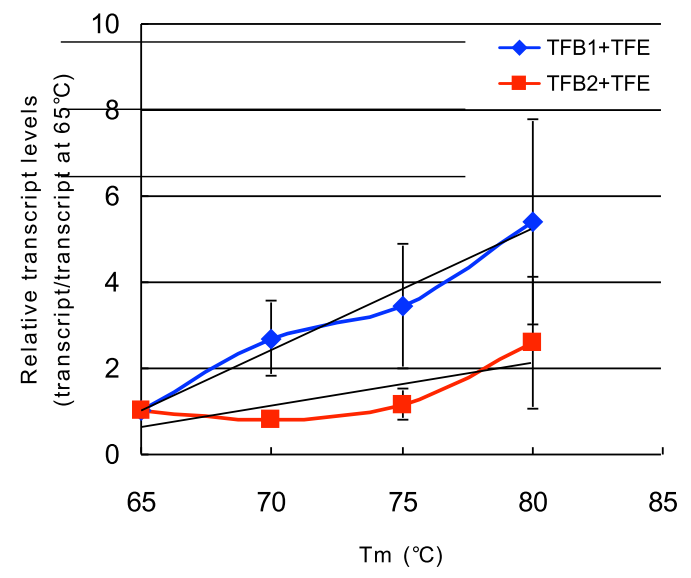


Figure 10. Transcription of the promoter for a heat-shock induced gene, Pf0687, using TFB1 or TFB2 in different temperatures. (A) Activities of the transcription complexes formed with TFB1, TFB2, TFB1+TFE, or TFB2+TFE with Pf0687 in different temperatures $\left(65-85^{\circ} \mathrm{C}\right)$ The promoter-dependent transcripts are indicated by the arrow. $\mathrm{X}$ : no TFB at $75^{\circ} \mathrm{C}, \mathrm{EX}$ : no TFB, but with TFE at $75^{\circ} \mathrm{C}, \mathrm{M} 1: 37 \mathrm{nt}$ marker, M2: $84 \mathrm{nt}$ marker. (B) Transcription activity comparison of TFB1 and TFB2 with Pf0687 in the presence and absence of TFE $(80 \mathrm{nt})$. The ratio of transcription activity with TFE to without TFE is shown. (C) Transcription response to temperature relative to $65^{\circ} \mathrm{C}$ of TFB1+TFE and TFB2+TFE with Pf0687 (80 nt). Quantitation of the transcription activity of different temperatures with Pf0687 normalized to the activity of its own activity at 65 ${ }^{\circ} \mathrm{C}$. (D) Transcription activity comparison of TFB1 and TFB2 with Pf0687 in the presence and absence of TFE (114 nt). The ratio of transcription activity with TFE to without TFE is shown. Blue represents TFB1, and red represents TFB2. (E) Transcription response to temperature relative to $65^{\circ} \mathrm{C}$ of TFB1+TFE and TFB2+TFE with Pf0687 (114 nt). Quantitation of the transcription activity of different temperatures with Pf0687 normalized to the activity of its own activity at $65^{\circ} \mathrm{C}$. Blue (diamond) represents TFB1, and red (square) represents TFB2. Error bars represent standard deviation (SD) from three independent experiments. Figure 6A and Figure 10A are the image from the same gel.

The promoter for the heat shock induced gene Pf1616 (a myo-inositol-1-phosphate synthase gene) was also tested for its response to TFE. The TFB1 activity in the presence of TFE increased with temperature, reaching the highest at $80^{\circ} \mathrm{C}$ (Fig 11A lane 18), and decreased at $85{ }^{\circ} \mathrm{C}$ (Fig 11A lane 19). The TFB2 activity in the presence of TFE with TFB2 increased at $75^{\circ} \mathrm{C}$ and $80{ }^{\circ} \mathrm{C}$ (Fig 11A lanes 23-24). The comparison between presence and absence of TFE indicated that the activity of the transcription complexes with TFB1 stayed the same or slightly increased, and the activity of the transcription complexes containing with TFB2 increased in all temperatures; particularly at lower temperatures $\left(65^{\circ} \mathrm{C}\right.$ and $\left.70^{\circ} \mathrm{C}\right)($ Fig 11B). The transcription response to temperature relative to $65{ }^{\circ} \mathrm{C}$ was similar for TFB1 and TFB2 in the presence of TFE, in contrast to the absence of TFE (Fig 11C). These results of Pf0687 and Pf1616 indicated that TFB2 behaves more similarly to TFB1 when TFE is present. 
A.

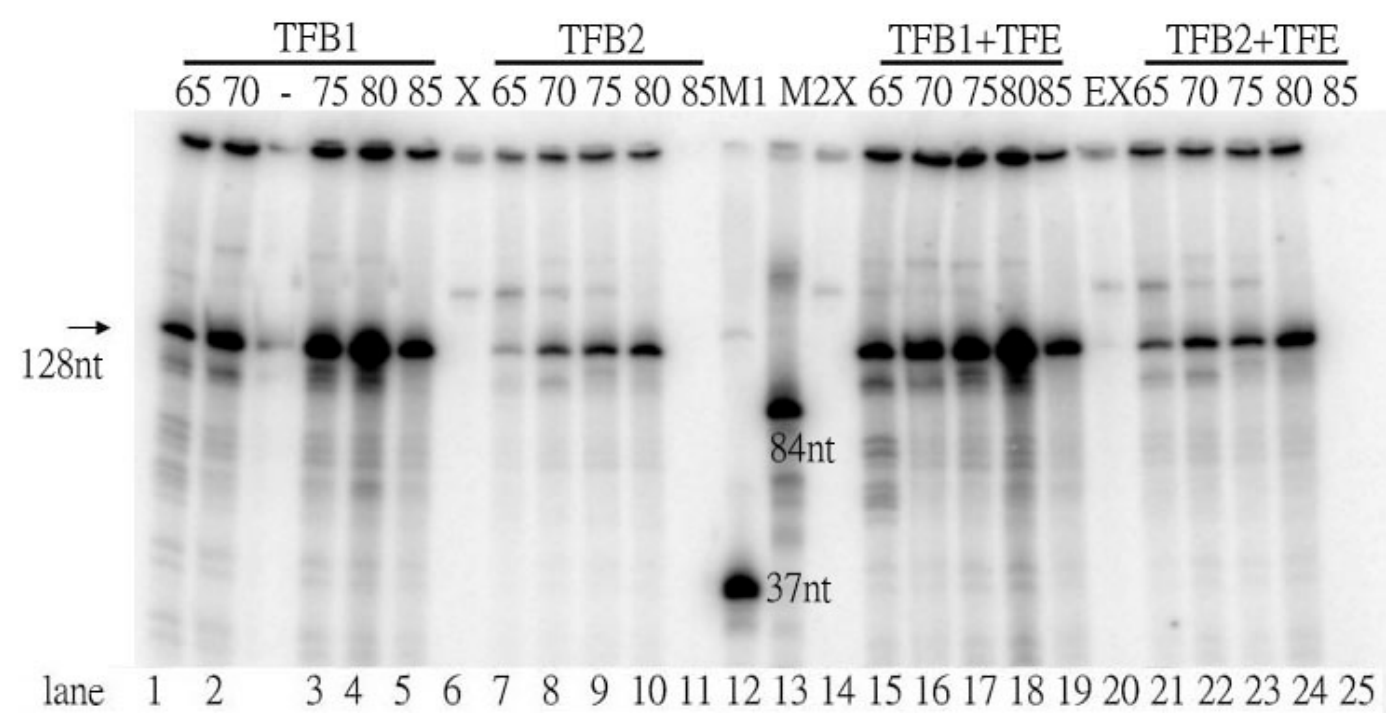

B.

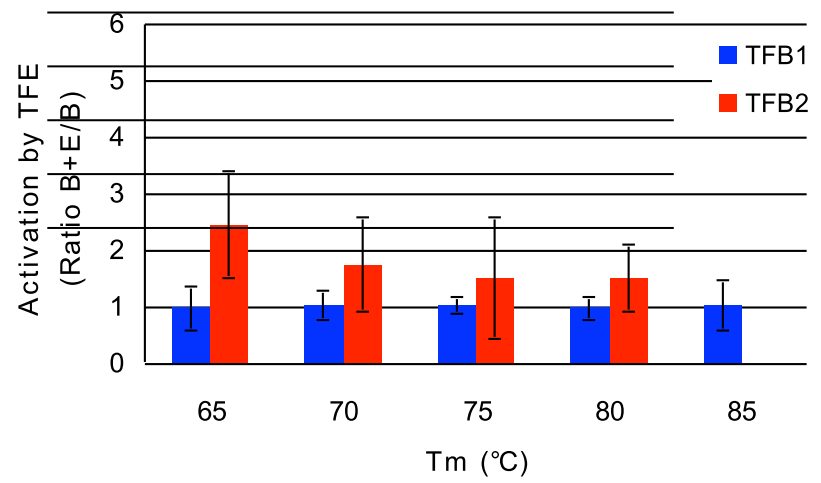

C.

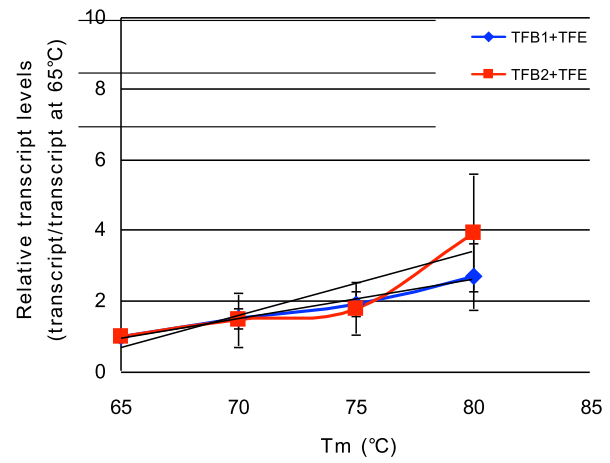

Figure 11. Transcription of the promoter for a heat-shock induced gene, Pf1616, using TFB1 or TFB2 in different temperatures. (A) Activities of the transcription complexes formed with TFB1, TFB2, TFB1+TFE, or TFB2+TFE with Pf1616 in different temperatures $\left(65-85^{\circ} \mathrm{C}\right)$ The promoter-dependent transcripts are indicated by the arrow. $\mathrm{X}$ : no TFB at $75^{\circ} \mathrm{C}, \mathrm{EX}$ : no TFB, but with TFE at $75^{\circ} \mathrm{C}, \mathrm{M} 1: 37 \mathrm{nt}$ marker, M2: $84 \mathrm{nt}$ marker. (B) Transcription activity comparison of TFB1 and TFB2 with Pf1616 in the presence and absence of TFE. The ratio of transcription activity with TFE to without TFE is shown. (C) Transcription response to temperature relative to $65^{\circ} \mathrm{C}$ of TFB1+TFE and TFB2+TFE with Pf1602. Quantitation of the transcription activity of different temperatures with Pf1616 normalized to the activity of its own activity at $65{ }^{\circ} \mathrm{C}$. Blue (diamond) represents TFB1, and red (square) represents TFB2. Error bars represent standard deviation (SD) from three independent experiments. Figure 7A and Figure 11A are the image from the same gel. 
The response of the promoter for cold-shock induced gene (Pf1137) was tested in the presence of TFE for both TFB1 and TFB2. For the short transcript (48 nt), although the activity of TFB2 was not rescued by TFE (Fig 12A lanes 21-25), the activity of TFB1 still behaved similarly when TFE was present or absent (Fig 12A lanes 1-5 \& 15-19, Fig 12B). However, for the long transcript (109 nt), when TFE was present, the activity of transcription complexes formed with TFB1 and TFB2 stayed almost the same. At $70{ }^{\circ} \mathrm{C}$, the activity of transcription complexes formed with TFB1 and TFE was even lower than those with TFB1 only (Fig 12D). Interestingly, the activity of transcription complexes with TFE but no TFB1 or TFB2 was slightly higher than those without TFE, TFB1 or TFB2. It showed that the promoter of cold-shock gene (PF1137) does not required TFB1, TFB2, or TFE (Fig 12A lanes 6, 20). However, with either of TFB1, TFB2, or TFE, the transcription activity will be increased. 
A. $\frac{\text { TFB1 }}{65-70758085} \times \frac{\text { TFB2 }}{6570758085 M 1 M 2 X} \frac{\text { TFB1+TFE }}{6570758085 \text { EX } 6570758085}$

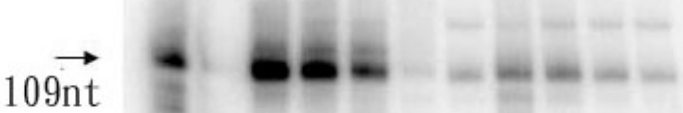
$48 \overrightarrow{n t}$

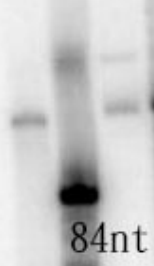

lane $11 \quad 2 \quad 2 \quad 3 \quad 4 \quad 5 \quad 6 \quad 7 \quad 8 \quad 9 \quad 10111213141516171819202122232425$

B.

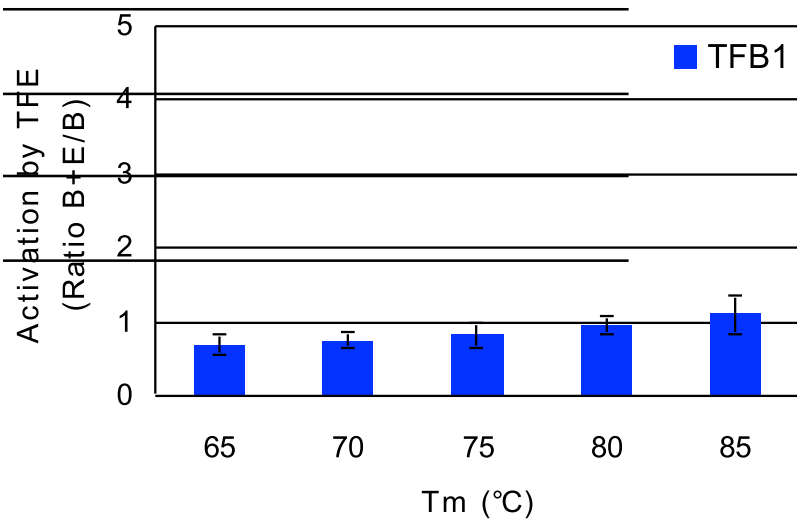

D.

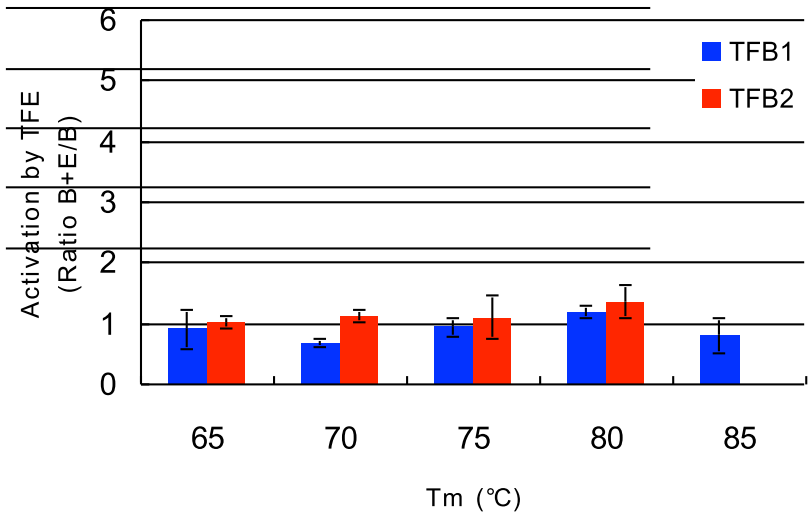

C.

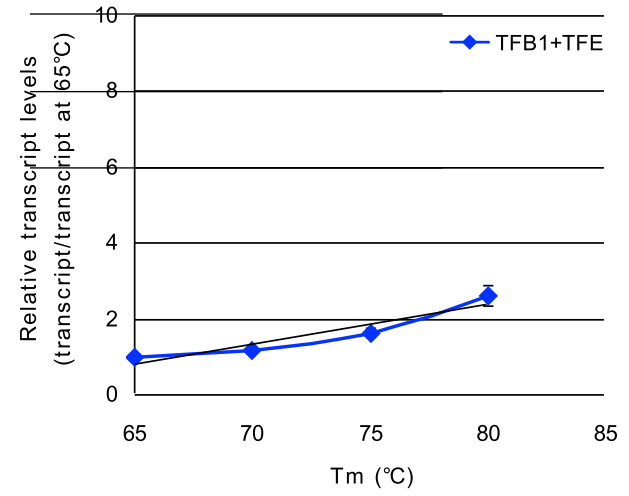

E.

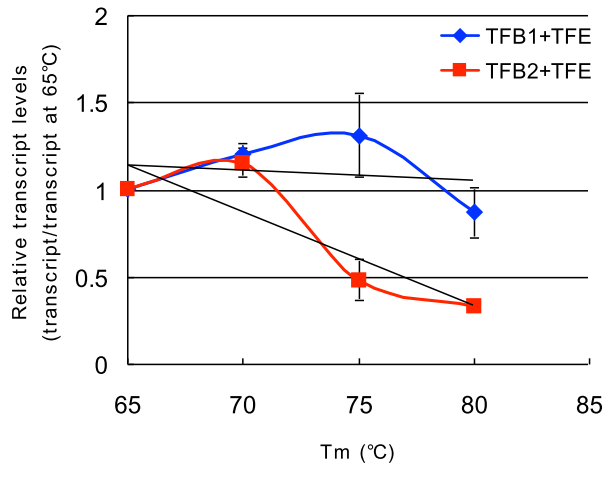


Figure 12. Transcription of the promoter for a cold-shock induced gene, Pf1137, using TFB1 or TFB2 in different temperatures. (A) Activities of the transcription complexes formed with TFB1, TFB2, TFB1+TFE, or TFB2+TFE with Pf1137 in different temperatures $\left(65-85^{\circ} \mathrm{C}\right)$ The promoter-dependent transcripts are indicated by the arrow. $\mathrm{X}$ : no TFB at $75^{\circ} \mathrm{C}, \mathrm{EX}$ : no TFB, but with TFE at $75^{\circ} \mathrm{C}, \mathrm{M} 1: 37 \mathrm{nt}$ marker, M2: $84 \mathrm{nt}$ marker. (B) Transcription activity comparison of TFB1 and TFB2 with Pf1137 in the presence and absence of TFE (48 nt). The ratio of transcription activity with TFE to without TFE is shown. (C) Transcription response to temperature relative to $65{ }^{\circ} \mathrm{C}$ of TFB1+TFE and TFB2+TFE with Pf1137(48 nt). Quantitation of the transcription activity of different temperatures with Pf1 137 normalized to the activity of its own activity at 65 ${ }^{\circ} \mathrm{C}$. (D) Transcription activity comparison of TFB1 and TFB2 with Pf1137 in the presence and absence of TFE (109 nt). The ratio of transcription activity with TFE to without TFE is shown. (E) Transcription response to temperature relative to $65^{\circ} \mathrm{C}$ of TFB1+TFE and TFB2+TFE with Pf1137(109 nt). Quantitation of the transcription activity of different temperatures with Pf1137 normalized to the activity of its own activity at $65{ }^{\circ} \mathrm{C}$. Blue (diamond) represents TFB1, and red (square) represents TFB2. Error bars represent standard deviation (SD) from three independent experiments. Figure 8A and Figure 12A are the image from same gel.

With TFE stabilizing the transcription preinitiation complex, the activity of transcription complexes with TFB1 was more active than with TFB2 in all temperatures and at four different promoters. TFE did not enhance the activity of TFB1 much, but it did enhance the activity of TFB2, particularly, at the lower temperatures $\left(65^{\circ} \mathrm{C}\right.$ and 70 $\left.{ }^{\circ} \mathrm{C}\right)$. Because the enhanced activities of TFB2 in lower temperatures, TFB1 and TFB2 behaved more similarly as a function of temperature in the presence of TFE. 


\section{CONCLUSION}

Transcription factor TFB2 is an alternative TFB encoded by the hyperthermophile archaeon P. furiosus. The mRNA levels of TFB2 increase following heat shock, but the interaction of TFB2 with temperature responsive promoters is not well-understood. The experiments presented here demonstrate that transcription complexes formed with TFB2 show a more pronounced increase in activity with increasing temperature compared to TFB1 (Fig 6, 7). The increase was seen only at promoters for genes that are induced following heat shock. These experiments also show that the enhanced activity with temperature is not seen in the presence of transcription factor TFE, because of a disproportionate increase in TFB2 activity at lower temperatures.

These data are consistent with previous data showing that the low activity of TFB2 is related to its low efficiency in forming open complexes, in which DNA is separated to form a transcription bubble (61). TFB2 loses more activity on heat shock promoters at low temperature, presumably because the open complex is harder to melt at the low temperature. Interestingly, this effect is only seem with the heat shock gene promoters, suggesting that promoter sequence may confer sensitivity to temperature change. It may be that these promoters have transcription rates limited by open complex formation, while other promoter are not as sensitive to perturbations at this stage of initiation.

The reduced activity of TFB2 at low temperature is probably a result of the missing domains within its N-terminus. Absence of the conserved B-reader loop may prevent efficient capture and stabilization of the transcription bubble by TFB2 at low 
temperature. The rescue of this defect by TFE is consistent with previous data showing that TFE can assist in promoter opening with TFB2 (61).

With all promoters tested (Pf0687, Pf1137, Pf1602, and Pf1616), the transcription activities of TFB1 are higher than the ones of TFB2 in all different temperatures. Also, for most promoters, the transcription activities of both TFB1 and TFB2 increased with increasing temperatures, with transcription at $85{ }^{\circ} \mathrm{C}$ reduced for TFB1, and more severely reduced for TFB2. An interesting exception was observed for the Pf1137 promoter region. The promoter yielding the larger transcript, while partly TFB-independent, had increased activity with both TFB1 and TFB2, and the highest activity was seen at $70{ }^{\circ} \mathrm{C}$. The increased activity of the promoter at lower temperatures is consistent with the coldshock induction of Pf1137 mRNA, and suggests that the response of this gene to cold shock could be explained by the intrinsic promoter sequence that forms transcription complexes more readily at low temperature. The mechanism for this sequence-dependent low temperature induction is unknown, but is likely to be interesting. To investigate this further, the transcription start site (TSS) will need to be mapped, and a more complete analysis of the determinations of initiation will need to be studied. For instance, is TBP required; or is RNA polymerase capable of initiating without assistance from transcription factors? Also, does the TFB-dependent activation require TBP? 


\section{TFB2 as a temperature response factor}

TFB1's transcription activity increased with increasing temperature in all four promoters (with the exception of Pf1137 alone). However, TFB2's transcription activity increased differently with increasing temperature in different promoters (Fig 5B, 6B, $7 \mathrm{~B}$ and $8 \mathrm{~B}$ ). In a previous study (Kottmeier, MS thesis, data 2009), the activities of transcription complexes with TFB1 or TFB2 with Pf1616 were slightly different. When comparing $55^{\circ} \mathrm{C}, 65^{\circ} \mathrm{C}$, and $75^{\circ} \mathrm{C}$, the activity of transcription complex containing TFB1 had the highest activity at $65^{\circ} \mathrm{C}$, and the activity of transcription complex containing TFB2 were very low for all three temperatures. However, I found that this result arose because transcription complexes formed with TFB2 are more sensitive to the poly-anion heparin than those formed with TFB1. When adding heparin into the transcription assay, the activity of transcription complex containing TFB2 was selectively decreased (Fig. 4). I predict that since TFB2-containing transcription complexes are compromised in promoter opening, they form less stable complexes, and heparin disrupts them more than the complexes formed with TFB1. Because of this, in this study, all the transcription assays in this thesis were done without adding heparin.

With the heat-shock induced promoters (Pf0687 and Pf1616 promoters), although TFB2 transcription complexes had lower activity than TFB1's, transcription with TFB2 increased more with increasing temperature compared to with TFB1(Fig 6B and 7B). This demonstrated that TFB2 is proportionally more active at high temperature when a heat-shock promoter is being transcribed. Therefore, upon heat shock in vivo, TFB2 may 
direct transcription of heat shock promoters, and when the temperature returns to normal, transcription of heat shock promoters with TFB2 may be shut off quickly.

With the non-temperature dependent promoter (Pf1602 promoter), the patterns of the activity relative to $65^{\circ} \mathrm{C}$ of TFB1 and TFB2 were more similar to each other, which indicated that the temperature change affects TFB1 and TFB2 similarly at this promoter (Fig 5B).

With the cold-shock promoter (Pf1137), for the short transcript (48 nt) transcription with TFB1 increased slowly with increasing temperature; but, TFB2 did not transcribe this promoter (Fig 8B). However, for the long transcript (114 nt) cold-shock promoter, TFB1 or TFB2 was not absolutely required for transcription (Fig 8A lane 6). Moreover, TFB1 and TFB2 increased transcript levels with highest activities at lower temperature (Fig $8 \mathrm{~A}$ lanes 1,27 , and 8 ). The pattern of the activity relative to $65^{\circ} \mathrm{C}$ of TFB1 and TFB2 were more similar, which indicated that the temperature change affects TFB1 and TFB2 similarly at this region of the cold-shock induced gene (Pf1137) (Fig 8C). It may be that the upstream promoter can form certain structure for RNA polymerase recruitment on it without TFB1 or TFB2. However, the downstream cold-shock relative promoter may not be recognized by TFB2 because of the missing B-reader region of TFB2. Taken together, these data suggest that TFB2 may play a role in heat-shock response through its modulation of genes important for heat shock survival, while cold shock induction may be modulated by promoter sequence independently of the TFB used for transcription. 


\section{The response of TFB2 to TFE}

In the presence of TFE, TFB2 complexes are more like TFB1 complexes in their response to changing temperature. For all promoters at each temperature tested, the ratio of transcription activity for TFB1 plus and minus TFE was close to one, because TFE has little effect on TFB1 transcription in vitro as previously observed (61). On the other hand, the ratio of activity for TFB2 plus and minus TFE varied in different promoters and temperatures (Fig 9B, 10B, 11B, and 12B). With the heat-shock promoters (Pf0687 and Pf1616), all the ratios of activity for TFB2 with TFE to without TFE were higher than those of TFB1, and increased most at $70{ }^{\circ} \mathrm{C}$ and $65^{\circ} \mathrm{C}$ in Pf0687 and PF1616 respectively. However, the ratio of activity for TFB2 comparing with TFE to without TFE, was lower at higher temperatures. (Fig 10B and 11B). Because of the increased transcription activity at lower temperatures, the transcription response relative to $65^{\circ} \mathrm{C}$ for TFB2 was more similar to that of TFB1 in both heat-shock promoters in the presence of TFE (Fig 10C and 11C).

With the non-temperature responsive gene promoter (Pf1602), the ratios of activity for TFB2 with TFE to without TFE increased the most at $70{ }^{\circ} \mathrm{C}$ and decreased at $75^{\circ} \mathrm{C}$ and $80{ }^{\circ} \mathrm{C}$. The transcription response relative to $65^{\circ} \mathrm{C}$ for TFB1 and TFB2 behaved similarly when TFE was absent (Fig 5B). With the presence of the TFE, the activity ratio relative to $65^{\circ} \mathrm{C}$ for TFB1 and TFB2 was even more similar (Fig 9C).

With the cold-shock relative gene promoter (Pf1137), TFB2 did not associate with the downstream promoter. However, for the upstream promoter, when TFE was present, the activity ratio relative to $65^{\circ} \mathrm{C}$ for TFB1 and TFB2 was similar (Fig 12E). 
These data indicate that TFE does not increase TFB1's transcription activity much, but does increase TFB2's transcription activity; especially, at the lower temperatures $\left(65^{\circ} \mathrm{C}\right.$ and $\left.70{ }^{\circ} \mathrm{C}\right)$. Some deductions are drawn from these results. First, TFB2 is associated with the heat-shock promoters and may play a role in the cellular heat-shock response. Second, TFE can stabilize the connection of PIC with TFB2 and make TFB2 work better in transcription at lower temperature. Third, TFB2 does not associate with cold-shock promoter even with TFE for downstream promoter, but behaves similarly to TFB1 with and without TFE at the upstream promoter. The function of the non-conserved B-reader region in TFB2 still remains unclear. One possibility is that the TFB2 B-reader / B-linker region interacts differently with the DNA of heat-shock promoters compared to non-heat-shock promoters. To test this, photo-cross linking assays may reveal the different interaction between TFB2 and the promoter DNA, and $\mathrm{KMnO}_{4}$ foot-printing assay can identify how well the non-conserved B-reader of TFB2 still functions in promoter opening. While the activity of TFB2 is lower than TFB1 in vitro, it is possible that its activity in vivo is higher during heat shock. Perhaps the shorter Breader / B-linker is less susceptible to unfolding at high temperature, or perhaps TFB2 interacts with an as yet unknown helper factor. 


\section{REFERENCES}

1. Woese, C. R., \& Fox, G. E. (1977). Phylogenetic structure of the prokaryotic domain: the primary kingdoms. Proc Natl Acad Sci U S A., 74(11), 5088-5090.

2. Woese, C. R., Kandler, O., \& Wheelis, M. L. (1990). Towards a natural system of organisms: proposal for the domains Archaea, Bacteria, and Eucarya. Proc Natl Acad Sci U S A., 87(12), 4576-4579.

3. DeLong, E. F. (1998). Everything in moderation: archaea as 'non-extremophiles'. Curr Opin Genet Dev., 8(6), 649-654.

4. Rothschild, L. J., \& Mancinelli, R. L. (2001). Life in extreme environments. Nature., 409(6823), 1092-1101.

5. Fox, G. E., Magrum, L. J., Balch, W. E., Wolfe, R. S., \& Woese, C. R. (1977). Classification of methanogenic bacteria by $16 \mathrm{~S}$ ribosomal RNA characterization. Proc Natl Acad Sci U S A., 74(10), 4537-4541.

6. Koonin, E. V., \& Wolf, Y. I. (2008). Genomics of bacteria and archaea: the emerging dynamic view of the prokaryotic world. Nucleic Acids Res., 36(21), 6688-6719. doi: 6610.1093/nar/gkn6668. Epub 2008 Oct 6623.

7. Waters, E., Hohn, M. J., Ahel, I., Graham, D. E., Adams, M. D., Barnstead, M., Beeson, M., Bibbs, L., Bolanos, R., Keller, M., Kretz, K., Lin, X., Mathur, E., Ni, J., Podar, M., Richardson, T., Sutton, G. G., Simon, M., Soll, D., Setter, K. O., Short, J. M., \& Noordewier, M. (2003). The genome of Nanoarchaeum equitans: insights into early archaeal evolution and derived parasitism. Proc Natl Acad Sci U S A., 100(22), 12984-12988. Epub 12003 Oct 12917.

8. Maeder, D. L., Anderson, I., Brettin, T. S., Bruce, D. C., Gilna, P., Han, C. S., Lapidus, A., Metcalf, W. W., Saunders, E., Tapia, R., \& Sowers, K. R. (2006). The Methanosarcina barkeri genome: comparative analysis with Methanosarcina acetivorans and Methanosarcina mazei reveals extensive rearrangement within methanosarcinal genomes. J Bacteriol., 188(22), 7922-7931. Epub 2006 Sep 7915.

9. Wosten, M. M. (1998). Eubacterial sigma-factors. FEMS Microbiol Rev., 22(3), 127-150.

10.Browning, D. F., \& Busby, S. J. (2004). The regulation of bacterial transcription initiation. Nat Rev Microbiol., 2(1), 57-65.

11.He, Y., Fang, J., Taatjes, D. J., \& Nogales, E. (2013). Structural visualization of key steps in human transcription initiation. Nature., 495(7442), 481-486. doi: 410.1038/ nature11991. Epub 12013 Feb 11927.

12.Asturias, F. J. (2004). RNA polymerase II structure, and organization of the preinitiation complex. Curr Opin Struct Biol., 14(2), 121-129.

13.Hahn, S. (2004). Structure and mechanism of the RNA polymerase II transcription machinery. Nat Struct Mol Biol., 11(5), 394-403

14.Cheung, A. C., \& Cramer, P. (2012). A movie of RNA polymerase II transcription. Cell., 149(7), 1431-1437. doi: 1410.1016/j.cell.2012.1406.1006. 
15.Roeder, R. G. (1996). The role of general initiation factors in transcription by RNA polymerase II. Trends Biochem Sci., 21(9), 327-335.

16.Klein, B. J., Bose, D., Baker, K. J., Yusoff, Z. M., Zhang, X., \& Murakami, K. S. (2011). RNA polymerase and transcription elongation factor Spt4/5 complex structure. Proc Natl Acad Sci U S A., 108(2), 546-550. doi: 510.1073/pnas.1013828108. Epub 1013822010 Dec 1013828127.

17.Grohmann, D., Nagy, J., Chakraborty, A., Klose, D., Fielden, D., Ebright, R. H., Michaelis, J. \& Werner, F. (2011). The initiation factor TFE and the elongation factor Spt4/5 compete for the RNAP clamp during transcription initiation and elongation. Mol Cell., 43(2), 263-274. doi: 210.1016/j.molcel.2011.1005.1030.

18.Hirtreiter, A., Damsma, G. E., Cheung, A. C., Klose, D., Grohmann, D., Vojnic, E., Vojnic, E., Cramer, P., \& Werner, F. (2010). Spt4/5 stimulates transcription elongation through the RNA polymerase clamp coiled-coil motif. Nucleic Acids Res., 38(12), 4040-4051. doi: 4010.1093/nar/gkq4135. Epub 2010 Mar 4042.

19.Yudkovsky, N., Ranish, J. A., \& Hahn, S. (2000). A transcription reinitiation intermediate that is stabilized by activator. Nature., 408(6809), 225-229.

20.Kuehner, J. N., Pearson, E. L., \& Moore, C. (2011). Unravelling the means to an end: RNA polymerase II transcription termination. Nat Rev Mol Cell Biol., 12(5), 283-294. doi: 210.1038/nrm3098. Epub 2011 Apr 1013.

21.Edwalds-Gilbert, G., Prescott, J., \& Falck-Pedersen, E. (1993). 3' RNA processing efficiency plays a primary role in generating termination-competent RNA polymerase II elongation complexes. Mol Cell Biol., 13(6), 3472-3480

22.Plant, K. E., Dye, M. J., Lafaille, C., \& Proudfoot, N. J. (2005). Strong polyadenylation and weak pausing combine to cause efficient termination of transcription in the human Ggamma-globin gene. Mol Cell Biol., 25(8), 3276-3285.

23.Steinmetz, E. J., \& Brow, D. A. (1996). Repression of gene expression by an exogenous sequence element acting in concert with a heterogeneous nuclear ribonucleoprotein-like protein, Nrd1, and the putative helicase Sen1. Mol Cell Biol., 16(12), 6993-7003.

24.Steinmetz, E. J., Conrad, N. K., Brow, D. A., \& Corden, J. L. (2001). RNA-binding protein Nrd1 directs poly(A)-independent 3'-end formation of RNA polymerase II transcripts. Nature., 413(6853), 327-331

25.Zhang, Z., Guo, L., \& Huang, L. (2012). Archaeal chromatin proteins. Sci China Life Sci., 55(5), 377-385. doi: 310.1007/s11427-11012-14322-y. Epub 12012 May 11427.

26.Cubonovaa, L., Katano, M., Kanai, T., Atomi, H., Reeve, J. N., \& Santangelo, T. J. (2012). An archaeal histone is required for transformation of Thermococcus kodakarensis. J Bacteriol., 194(24), 6864-6874. doi: 6810.1128/JB.01523-01512. Epub 02012 Oct 01512.

27.Sandman, K., \& Reeve, J. N. (2006). Archaeal histones and the origin of the histone fold. Curr Opin Microbiol., 9(5), 520-525. Epub 2006 Aug 2022.

28.Cubonova, L., Sandman, K., Hallam, S. J., Delong, E. F., \& Reeve, J. N. (2005).

Histones in crenarchaea. J Bacteriol., 187(15), 5482-5485. 
29.Gribaldo, S., \& Brochier-Armanet, C. (2006). The origin and evolution of Archaea: a state of the art. Philos Trans R Soc Lond B Biol Sci., 361(1470), 1007-1022.

30.Myllykallio, H., Lopez, P., Lopez-Garcia, P., Heilig, R., Saurin, W., Zivanovic, Y., . . . Forterre, P. (2000). Bacterial mode of replication with eukaryotic-like machinery in a hyperthermophilic archaeon. Science., 288(5474), 2212-2215.

31.Bell, S. D., \& Jackson, S. P. (2001). Mechanism and regulation of transcription in archaea. Curr Opin Microbiol., 4(2), 208-213.

32.Thomm, M., Reich, C., Grunberg, S., \& Naji, S. (2009). Mutational studies of archaeal RNA polymerase and analysis of hybrid RNA polymerases. Biochem Soc Trans., 37(Pt 1), 18-22. doi: 10.1042/BST0370018.

33. Ouhammouch, M. (2004). Transcriptional regulation in Archaea. Curr Opin Genet Dev., 14(2), 133-138.

34.Bell, S. D., Brinkman, A. B., van der Oost, J., \& Jackson, S. P. (2001). The archaeal TFIIEalpha homologue facilitates transcription initiation by enhancing TATA-box recognition. EMBO Rep., 2(2), 133-138.

35.Bell, S. D., Cairns, S. S., Robson, R. L., \& Jackson, S. P. (1999). Transcriptional regulation of an archaeal operon in vivo and in vitro. Mol Cell., 4(6), 971-982.

36.Brinkman, A. B., Dahlke, I., Tuininga, J. E., Lammers, T., Dumay, V., de Heus, E., . . . van Der Oost, J. (2000). An Lrp-like transcriptional regulator from the archaeon Pyrococcus furiosus is negatively autoregulated. J Biol Chem., 275(49), 38160-38169.

37.Dahlke, I., \& Thomm, M. (2002). A Pyrococcus homolog of the leucine-responsive regulatory protein, LrpA, inhibits transcription by abrogating RNA polymerase recruitment. Nucleic Acids Res., 30(3), 701-710.

38.Napoli, A., van der Oost, J., Sensen, C. W., Charlebois, R. L., Rossi, M., \& Ciaramella, M. (1999). An Lrp-like protein of the hyperthermophilic archaeon Sulfolobus solfataricus which binds to its own promoter. J Bacteriol., 181(5), 1474-1480.

39.Bushnell, D. A., Westover, K. D., Davis, R. E., \& Kornberg, R. D. (2004). Structural basis of transcription: an RNA polymerase II-TFIIB cocrystal at 4.5 Angstroms. Science., 303(5660), 983-988.

40.Kostrewa, D., Zeller, M. E., Armache, K. J., Seizl, M., Leike, K., Thomm, M., \& Cramer, P. (2009). RNA polymerase II-TFIIB structure and mechanism of transcription initiation. Nature., 462(7271), 323-330. doi: 310.1038/nature08548.

41.Liu, X., Bushnell, D. A., Wang, D., Calero, G., \& Kornberg, R. D. (2010). Structure of an RNA polymerase II-TFIIB complex and the transcription initiation mechanism. Science., 327(5962), 206-209. doi: 210.1126/science.1182015. Epub 1182009 Nov 1182012.

42.Sainsbury, S., Niesser, J., \& Cramer, P. (2013). Structure and function of the initially transcribing RNA polymerase II-TFIIB complex. Nature., 493(7432), 437-440. doi: 410.1038/nature11715. Epub 12012 Nov 11714. 
43.Hausner, W., Wettach, J., Hethke, C., \& Thomm, M. (1996). Two transcription factors related with the eucaryal transcription factors TATA-binding protein and transcription factor IIB direct promoter recognition by an archaeal RNA polymerase. J Biol Chem., 271(47), 30144-30148.

44.Littlefield, O., Korkhin, Y., \& Sigler, P. B. (1999). The structural basis for the oriented assembly of a TBP/TFB/promoter complex. Proc Natl Acad Sci U S A., 96(24), 13668-13673.

45.Kosa, P. F., Ghosh, G., DeDecker, B. S., \& Sigler, P. B. (1997). The 2.1-A crystal structure of an archaeal preinitiation complex: TATA-box-binding protein/transcription factor (II)B core/TATA-box. Proc Natl Acad Sci U S A., 94(12), 6042-6047.

46.Ohkuma, Y. (1997). Multiple functions of general transcription factors TFIIE and TFIIH in transcription: possible points of regulation by trans-acting factors. $J$ Biochem., 122(3), 481-489.

47.Grunberg, S., Bartlett, M. S., Naji, S., \& Thomm, M. (2007). Transcription factor E is a part of transcription elongation complexes. J Biol Chem., 282(49), 35482-35490. Epub 32007 Oct 35485.

48.Cabart, P., \& Luse, D. S. (2012). Inactivated RNA polymerase II open complexes can be reactivated with TFIIE. J Biol Chem., 287(2), 961-967. doi: 910.1074/ jbc.M1111.297572. Epub 292011 Nov 297527.

49.Jun, S. H., Reichlen, M. J., Tajiri, M., \& Murakami, K. S. (2011). Archaeal RNA polymerase and transcription regulation. Crit Rev Biochem Mol Biol., 46(1), 27-40. doi: 10.3109/10409238.10402010.10538662.

50.Feklistov, A., \& Darst, S. A. (2011). Structural basis for promoter-10 element recognition by the bacterial RNA polymerase sigma subunit. Cell., 147(6), 1257-1269. doi: 1210.1016/j.cell.2011.1210.1041. Epub 2011 Dec 1251.

51.Osterberg, S., del Peso-Santos, T., \& Shingler, V. (2011). Regulation of alternative sigma factor use. Annu Rev Microbiol, 65:37-55.(doi), 10.1146/annurev.micro. 112408.134219.

52.Decker, K. B., \& Hinton, D. M. (2013). Transcription regulation at the core: similarities among bacterial, archaeal, and eukaryotic RNA polymerases. Annu Rev Microbiol, 67:113-39.(doi), 10.1146/annurev-micro-092412-155756. Epub 092013 Jun 092413.

53.Baliga, N. S., Goo, Y. A., Ng, W. V., Hood, L., Daniels, C. J., \& DasSarma, S. (2000). Is gene expression in Halobacterium NRC-1 regulated by multiple TBP and TFB transcription factors? Mol Microbiol., 36(5), 1184-1185.

54.Santangelo, T. J., Cubonova, L., James, C. L., \& Reeve, J. N. (2007). TFB1 or TFB2 is sufficient for Thermococcus kodakaraensis viability and for basal transcription in vitro. J Mol Biol., 367(2), 344-357. Epub 2006 Dec 2030.

55.Gotz, D., Paytubi, S., Munro, S., Lundgren, M., Bernander, R., \& White, M. F. (2007). Responses of hyperthermophilic crenarchaea to UV irradiation. Genome Biol, 8(10), R220. 
56.Brunner, M., \& Bujard, H. (1987). Promoter recognition and promoter strength in the Escherichia coli system. EMBO J., 6(10), 3139-3144.

57.Cowing, D. W., Bardwell, J. C., Craig, E. A., Woolford, C., Hendrix, R. W., \& Gross, C. A. (1985). Consensus sequence for Escherichia coli heat shock gene promoters. Proc Natl Acad Sci U S A., 82(9), 2679-2683.

58.Ao, X., Li, Y., Wang, F., Feng, M., Lin, Y., Zhao, S., Liang, Y., \& Peng, N. (2013). The sulfolobus initiator element is an important contributor to promoter strength. J Bacteriol., 195(22), 5216-5222. doi: 5210.1128/JB.00768-00713. Epub 02013 Sep 00713.

59.Venters, B. J., \& Pugh, B. F. (2013). Genomic organization of human transcription initiation complexes. Nature., 502(7469), 53-58. doi: 10.1038/nature12535. Epub 12013 Sep 12518.

60.Shockley, K. R., Ward, D. E., Chhabra, S. R., Conners, S. B., Montero, C. I., \& Kelly, R. M. (2003). Heat shock response by the hyperthermophilic archaeon Pyrococcus furiosus. Appl Environ Microbiol., 69(4), 2365-2371.

61.Micorescu, M., Grunberg, S., Franke, A., Cramer, P., Thomm, M., \& Bartlett, M. (2008). Archaeal transcription: function of an alternative transcription factor B from Pyrococcus furiosus. J Bacteriol., 190(1), 157-167. Epub 2007 Oct 2026.

62.Hethke, C., Geerling, A. C., Hausner, W., de Vos, W. M., \& Thomm, M. (1996). A cell-free transcription system for the hyperthermophilic archaeon Pyrococcus furiosus. Nucleic Acids Res., 24(12), 2369-2376.

63.Weinberg, M. V., Schut, G. J., Brehm, S., Datta, S., \& Adams, M. W. W. (2005). Cold shock of a hyperthermophilic archaeon: Pyrococcus furiosus exhibits multiple responses to a suboptimal growth temperature with a key role for membrame-bound glycoproteins. J Bacteriol., 187(1), 336-348.

64.Robb, F. F., Maeder, D. L., Brown, J. R., Di Ruggiero, J., Stump, M. D., Yeh R. K., Weiss, R. B., \& Dunn, D. M. (2001). Genomic sequence of hyperthermophile, Pyrococcus furiosus: implications for physiology and enzymology. Methods Enzymol., 330, 134-157.

65.Lifton, R. P., Goldberg, M. L., Karp, R. W., \& Hogness, D. S. (1978). The organization of the histone gene in Drosophila melanogaster: Functional and evolutionary implications. Cold Spring Harb Symp Quant Biol., 42, 1047-1051.

66.Lagarange, T., Kapanidis A. N., Tang, H., Reinberg, D., \& Ebright R. H. (1998). New core promoter element in RNA polymerase II- dependent transcription: sequencespecific DNA binding by transcription factir IIB. Genes Dev., 12(1), 34-44.

67.Werner, F., \& Weinzierl, R. O.(2005). Direct modulation of RNA polymerase core functions by basal transcription factors. Mol Cell Biol., 25(18), 8344-55

68.Bartlett, M. S., Thomm. M., \& Geiduschek. E. P. (2000). The orientation of DNA in an archaeal transcription initiation complex. Nat Struct Biol., 7(9),782-785

69.Fan, L., Arvai, A. S., Cooper, P. K., Iwai, S., Hanaoka, F., \& Trainer, J. A. (2006). Conserved XPB core structure and motifs for DNA unwinding: implications for pathway selection of transcription or excision repair. Mol Cell., 22(1), 27-37 
70.Soppa, J., Kobayashi, K., Noiorot-Gros, M. F., Oesterhelt, D., Ehrlich, S. D., Ogasawara, N., \& Moriya, S. (2002). Discovery of two novel families of proteins that are proposed to interact with prokaryotic SMC proteins, and characterization of Bacillus subtilis family member ScpA and ScpB. Mol Microbiol., 45(1), 59-71

71.Naidu, S., Friedrich, J. K., Russell, J., \& Zomerdijk, J. C. (2011). TAF1B is a TFIIBlike component of the basal transcription machinery for RNA polymerase I. Science. 333(6049), 1640-1642.

72.Knutson, B. A., \& Hahn, S. (2011). Yeast Rrn7 and human TAF1B are TFIIB-related RNA polymerase I general transcription factors. Science., 333(6049), 1637-1640

73.Kassavetis, G. A., Kumar, A., Ramirez, E., \& Geiduschek, E. P. (1998). Functional and structural organization of Brf, the TFIIB-related component of the RNA polymerase III transcription initiation complex. Mol Cell Biol., 18(9), 5587-5599.

74.Langer, D., Hain, J., Thuriaux, P., \& Zillig, W. (1995). Transcription in archaea: similarity to that in eucarya. Proc Natl Acad Sci U S A., 92(13), 5768-5772 


\section{Appendix A:}

\section{The function of aromatic amino acids in archaeal TFB B-reader motif}

In bacterial transcription initiation, the substitutions of -11A of the promoter and Y430 and W433 of sigma70 affect the transcription efficiency. These aromatic amino acids of sigma 70 factor and the $-11 \mathrm{~A}$ of the promoter work together during promoter opening. Archaeal TFB and Eukaryotic TFIIB N-terminal regions contain three highly conserved motif, B-ribbon, B-reader, and B-linker. (Fig. 2) There are two highly conserved aromatic amino acids, tryptophan (W) and phenylalanine (F), in the B-reader region of the TFB and TFIIB in archaea and eukaryotes. We predict that the tryptophan and phenylalanine may play roles during the promoter opening step of transcription initiation in Pyrococcus furiosus, and that the aromatic group of these amino acids is crucial for this process. For testing this hypothesis, we generated four different TFB mutant proteins, W44A, W44A F47A, W44F, and W44F F47W to see if they can affect the transcription in different concentrations $(60 \mathrm{nM}$ and $120 \mathrm{nM})$. In this result, the activity with the W44A F47A mutant was decreased the most when the concentration of TFB1 mutant was 60nM and 120nM (Fig 13 lanes 3 and 9). The W44A TFB1 mutant had the second lowest activity in both 60 and $120 \mathrm{nM}$ (Fig 13 lanes 2 and 8). However, the aromatic amino acid switch mutants (W44F, W44F F47W) had lower activity than the wild type TFB1, but higher activity than W44A and W44A F47A TFB1 mutants in 60nM and 120nM (Fig 13 lanes 4, 5, 10, and 11). This result showed that aromatic amino acids W44 and F47 in B-reader helix motif play a key role in transcription, although positioning of these amino acids during promoter opening has not yet been established. 


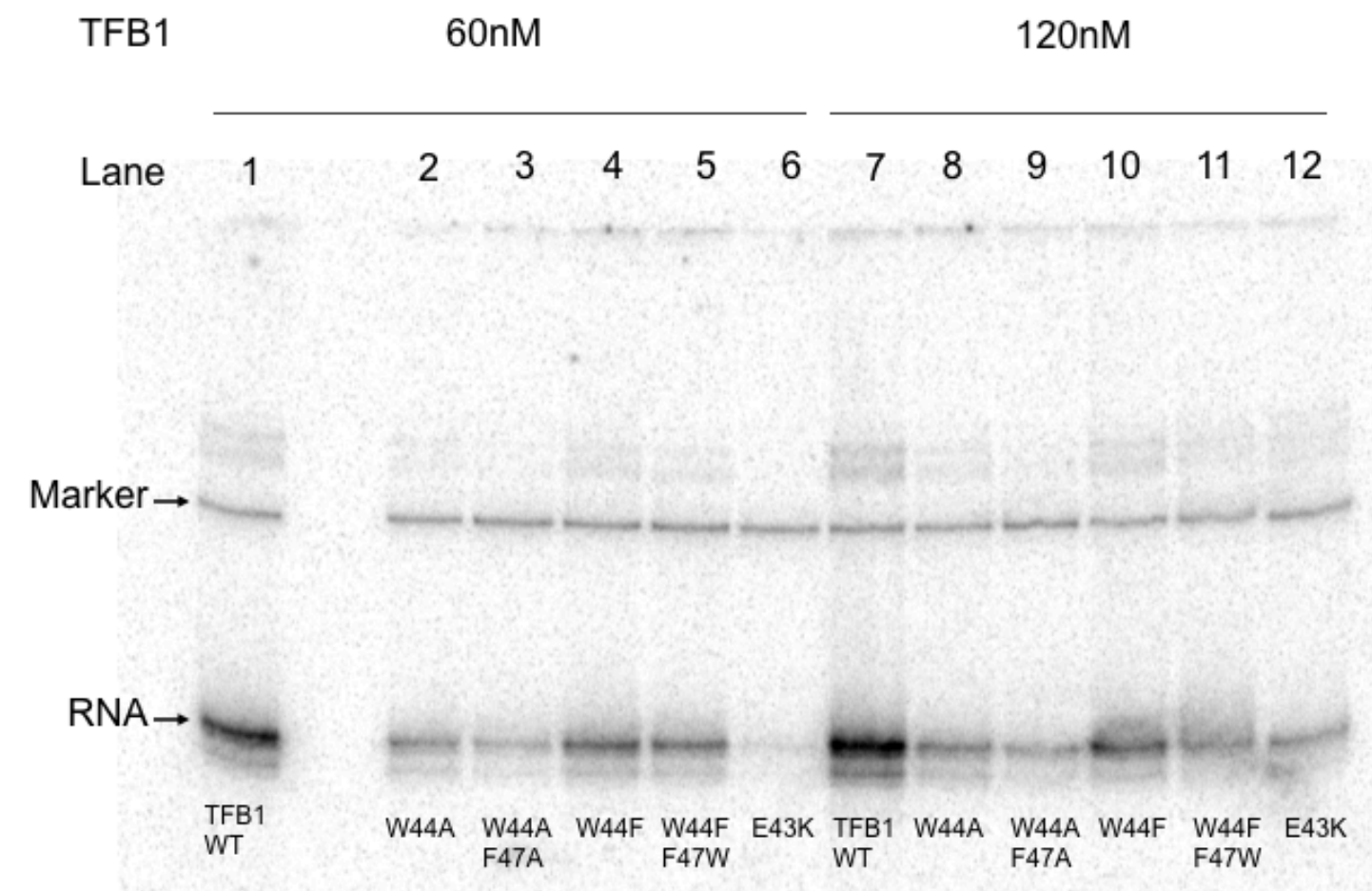

Figure 13. Transcription activity of Pf1602 promoter with TFB mutants. 


\section{Appendix B:}

\section{The function of XPB and XPD in Archaea}

In Eukaryotes, RNA polymerase II and several general transcription factors catalyze the transcription of messenger RNA). Transcription factor IIH (TFIIH), one of these transcription factors, is involved in not only transcription initiation but also nucleotide excision repair (NER). Certain mutations of TFIIH cause human genetic disorders xeroderma pigmentosum (XP), Cockayne syndrome (CS), and trichothiodystrophy (TTD). XPB and XPD (xeroderma pigmentosum groups B and D) are the two largest subunits of TFIIH. Both of them have helicase and ATPase activity. Moreover, both play a role in opening the promoter during transcription initiation and unwinding damaged DNA in NER.

Most Archaea contain aXPB and aXPD genes which are the homologues of eukaryotic XPB and XPD. Because of the conservation of sequences of XPB and XPD in archaea and eukaryotes and the similarity of transcription mechanism between archaea and eukaryotes, I predict that aXPB and aXPD may have similar transcription functions in archaea as in eukaryotes. The function of aXPB and aXPD in archaeal NER is starting to be researched; however, their function in transcription is still unknown (69).

Archaeal XPB and XPD gene homologs were cloned into E.coli over-expression plasmids, producing six-histidine tagged version of these proteins. I have tried different protein purifications (non-denaturing and denaturing). Several other proteins from the E.coli host were co-purified with aXPB or aXPD. Moreover, without the IPTG induction, either aXPB or aXPD appeared to still be expressed which made aXPB and aXPD even 
more difficult to identify. An example native purification of XPB and XPD is shown in Fig. 14.

A.
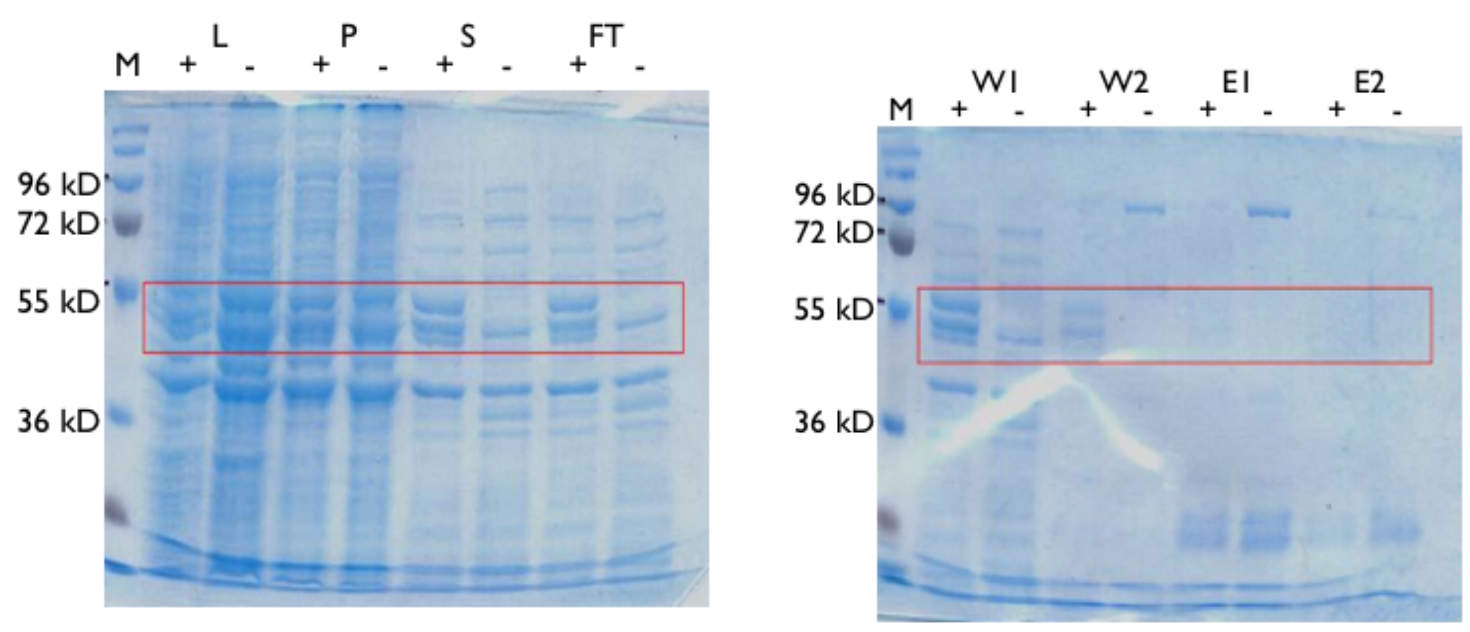

B.
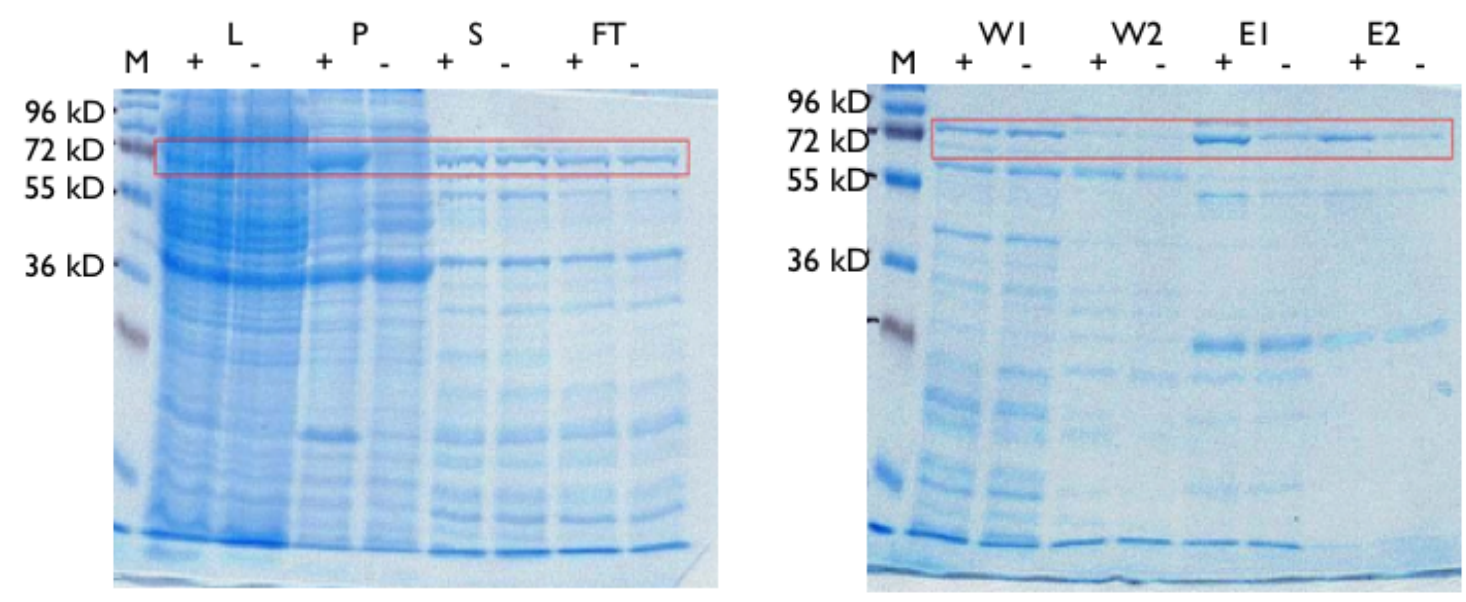

Figure 14. SDS-PAGE gel of aXPB and aXPD purification. (A). aXPB purification in native condition. aXPB: $51.8 \mathrm{kD}$. (B) aXPD purification in native condition. aXPD: $72.8 \mathrm{kD}$. + : use IPTG to induce E.coli to produce aXPB; - : No IPTG. L: lysate ; P : pellet ; S: supernatant of the liquid inside of E.coli; FT: flow through; W1: use $10 \mu \mathrm{M}$ imidazole to wash column; W2: use $20 \mu \mathrm{M}$ imidazole to wash; E1 and E2: use $200 \mu \mathrm{M}$ imidazole elute the protein with an affinity tag. 